\title{
Continuous Emission Monitor for Toxic Metals in the Off- Gases of Thermal Treatment Facilities
}

\author{
Final Report \\ July 1997 \\ By
Gary Loge
}

Work Performed Under Contract No.: DE-AC21-94MC32194

\author{
For \\ U.S. Department of Energy \\ Office of Fossil Energy \\ Federal Energy Technology Center \\ P.O. Box 880 \\ Morgantown, West Virginia 26507-0880
}

By

Laser Diagnostics, L.L.C.

35 Bonnie View Drive

Suite B

Los Alamos, New Mexico 87544 


\section{Disclaimer}

This report was prepared as an account of work sponsored by an agency of the United States Government. Neither the United States Government nor any agency thereof, nor any of their employees, makes any warranty, express or implied, or assumes any legal liability or responsibility for the accuracy, completeness, or usefulness of any information, apparatus, product, or process disclosed, or represents that its use would not infringe privately owned rights. Reference herein to any specific commercial product, process, or service by trade

name, trademark, manufacturer, or otherwise does not necessarily constitute or imply its endorsement, recommendation, or favoring by the United States Government or any agency thereof. The views and opinions of authors expressed herein do not necessarily state or reflect those of the United States Government or any agency thereof. 


\title{
CONTINUOUS EMISSION MONITOR FOR TOXIC METALS IN THE OFF-GASES OF THERMAL TREATMENT FACILITIES
}

\author{
FINAL REPORT \\ Contract No. DE-AC21-94MC32194--99
}

Gary Loge, Ph.D.

Principal Investigator

July, 1997

Laser Diagnostics, L.L.C.

35 Bonnie View Dr., Suite B

P. O. Box 4627

Los Alamos, NM 87544 


\begin{abstract}
Self-calibration procedures for continuous monitoring of toxic metals in the off-gases of thermal treatment facilities using laser-induced breakdown spectroscopy (LIBS) were tested. The tests were performed using a heated aerosol/gas flow system that generated simulated off-gas conditions with calibrated amounts of metal in an optical cell. Calibration curves of LIBS signal for metal concentration in the cell were obtained for various gas and optical conditions. Gas conditions that were varied include water in either vapor and condensed aerosol droplet form, the presence of easily ionizable elements (i. e., potassium), speciation of the metal analyte, and the gas temperature. In addition, laser pulse energy, focal length, and detector alignment were independently varied.

Two different sets of calibration curves were obtained, one set with $\mathrm{Mn}(\mathrm{II})$ and N(II) emission obtained simultaneously and a second set with $\mathrm{Cd}(\mathrm{I})$ and $\mathrm{Cd}(\mathrm{II})$ emission obtained simultaneously with N(I) emission obtained in a sequential manner. For both sets of data, calibration curves were obtained using 1) single line intensities, 2) the ratio of metal single line intensity to nitrogen single line intensity, and 3) the ratio of total metal emission to total nitrogen emission obtained using the temperature and electron density. Results show that correction using the ratio of metal single line intensity to nitrogen single line intensity does help in maintaining a constant slope of calibration curves for various conditions. However, the total emission self-calibration procedure shows better performance in most cases.
\end{abstract}




\section{EXECUTIVE SUMMARY}

Laser-Induced Breakdown Spectroscopy, LIBS, which uses atomic emission lines from a spark generated at the focus of pulsed laser, is one method that may useful for continuously monitoring toxic metals in the off-gases of thermal treatment facilities. One problem that needs to be addressed before LIBS will be useful for this purpose is reliable calibration of the metal emission intensity to determine the metal concentration. This is more difficult for an in situ monitoring technique like LIBS, because varying gas and optical conditions can affect the calibration (matrix effects) and cannot be easily mimicked in an external calibration system.

Using a patented procedure that uses nitrogen emission (or some other element that has a constant number density in the off-gas) as a reference signal and that corrects for the plasma spark temperature and electron density, it should be possible to adjust LIBS signals to maintain a reliable calibration (calibration curve slope) independent of gas or optical conditions. To test self-calibration procedures, an aerosol generator and heated gas system were constructed to deliver a controlled gas aerosol stream into an optical cell where LIBS tests were performed. Various gas conditions were used to test the self-calibration procedure. They were wet aerosol, heated gas with various amounts of water vapor, dry gas containing only metal salt particles and nitrogen carrier gas, gas containing added potassium (an easily ionizable element that may affect the laser spark electron density), and speciation of metal as $\mathrm{MnCl}_{2}$ or $\mathrm{Mn}\left(\mathrm{NO}_{3}\right)_{2}$. In addition, the laser energy and detector alignment were varied to further test the atomic emission self-calibration procedure. Two sets of tests were performed, one for $\mathrm{Mn}(\mathrm{II})$ emission and one for $\mathrm{Cd}(\mathrm{I})$ and $\mathrm{Cd}(\mathrm{II})$ emission.

For the manganese tests, calibrations curves were obtained using laser spark emission spectra spanning the region from $240 \mathrm{~nm}$ to $384 \mathrm{~nm}$, which includes two Mn(II) lines and two N(II) lines needed for the plasma characterization (temperature and volume), for various gas and laser conditions. To detect the short-lived N(II) emission and still ensure thermal equilibrium in the plasma, the optimum delay for the detector gate was found to be 1.75 microseconds after the laser pulse. For this short delay time, significant broadband 
plasma emission remained, increasing the noise and baseline determination error. The temperature was determined using the two N(II) lines. The electron density in the laserinduced plasma was not determined, so equilibrium between neutral atom and ion number density was approximated using an empirical fit to all the calibration curve slopes.

For the Cd tests, $\mathrm{Cd}(\mathrm{I})$ and $\mathrm{Cd}(\mathrm{II})$ emission in the $190 \mathrm{~nm}-262 \mathrm{~nm}$ region was used. Also, longer-lived $\mathrm{N}(\mathrm{I})$ emission in the visible spectral region above $380 \mathrm{~nm}$ was used as the internal standard. Using the N(I) emission allowed a longer delay time of ten microseconds to be used, which had the advantage of less broadband plasma emission. The disadvantage of using N(I) emission was that the spectrograph grating had to be moved to a different spectral region from that used for the $\mathrm{Cd}(\mathrm{I})$ and $\mathrm{Cd}(\mathrm{II})$ measurements. The ratio of $\mathrm{Cd}$ (I) emission at $228 \mathrm{~nm}$ and $\mathrm{Cd}(\mathrm{II})$ emission at $214 \mathrm{~nm}$ and $226 \mathrm{~nm}$ was used to determine the electron density. The temperature was determined from the slope of an Arhennius plot using four N(I) emission lines and was found to be accurate to better than $250^{\circ} \mathrm{C}$ when using the laser at full power.

For both sets of tests, the metal concentration in the test cell was independently determined using filters to collect the metal salt flowing through the cell for a measured time, which allows the metal density in the gas flow to be determined. By also measuring the uptake rate of standard metal salt solutions for a constant 1.0 SLM nitrogen carrier gas flow rate, the efficiency of getting metal salt from the nebulizer to the optical cell was determined. This avoided the expense and inconvenience of performing a filter calibration for every run. However, this assumption of unchanging efficiency of getting metal salt from the nebulizer to the cell added an estimated $15 \%$ relative error to the calibration tests.

As expected, uncorrected, single atomic emission line calibration curves showed slopes that changed for some conditions, giving unreliable calibration. The ratio of single atomic emission line divided by single nitrogen emission line intensity showed less change in calibration for the manganese tests but still had some change in calibration slope for the cadmium tests. The self-calibration procedure, which also corrected for changing spark temperature showed the least variation in calibration slope, which was constant within the 
uncertainty of the amount of metal in the cell using the filter collection method except for lower laser energy in the cadmium tests, where the plasma temperature was less than the nitrogen dissociation energy and not well characterized.

Further improvements of this technique for monitoring off-gases will be to 1) use a higher resolution spectrograph $(0.1 \mathrm{~nm}$ or better) to increase the line intensity and separation, 2) use Fe (I) and Fe (II) emission to determine the electron density and the plasma temperature, 3) use an echelle spectrograph and gated array detector to obtain high resolution spectra in the range from $200 \mathrm{~nm}$ to $750 \mathrm{~nm}$ with a single laser pulse. The first and second improvements are planned for a demonstration at the EPA research incinerator at Research Triangle Park in September, 1997.

The next stage of development for this project will be to automate the line intensity self-calibration procedure for all the metals of interest, which involves software development. It will use an atomic emission line database to identify toxic metals and interfering atomic emission from other elements and will also use chemometrics to improve the analysis. The resulting software should allow automated metal identification and reliable concentration determination using the self-calibration procedure. 


\section{DEFINITION OF TERMS AND ABBREVIATIONS}

\section{Terms:}

Calibration

A determination of the relationship between the measured emission intensity and the metal concentration.

$\underline{\text { Self-calibration }}$

A sensor that has the capability to correct for changing calibration using a technique that does not involve using an external calibration source has self-calibration capability. Usually this is accomplished using a known reference signal that is either part of the sensor or in the sample being measured.

Flat-field correction

A flat-field correction corrects for 1) the spectrometer image onto the detector array being out-of-focus towards the ends of the array causing the image overfill the detector, 2) the collection optics and spectrometer not having flat transmission and reflection across the wavelength span of the spectrometer and array detector, 3) the detector not having a flat response across the wavelength span.

\section{Temperature-corrected emission}

A relative emission strength that is proportional to the total concentration of a neutral atom or ion in all thermally populated energy states. It is obtained from a single emission line by dividing by the line strength and the fractional population in the emitting upper state, with a statistical thermal population distribution (Boltzmann distribution) assumed.

Detection limit

$\mathrm{S} / \mathrm{N}=1$, estimated by extrapolating the signal back to the observed noise level.

$\underline{\text { Internal standard }}$

An element that is present in the sample at a constant and known concentration. Emission intensity from this element should remain constant if calibration is not changing. Off-gas 
The exhaust gas from a thermal treatment facility that is released into the atmosphere.

\section{Thermal treatment facilities}

Facilities that treat solid waste at elevated temperatures are collectively referred to as thermal treatment facilities. They include incinerators (rotary kiln and plasma torch), some cement kilns, and vitrification plants.

\section{Abbreviations:}

AR: Anti-reflective

CEM: Continuous Emission Monitor

CAA: The Clean Air Act (and its amendments)

EPA: Environmental Protection Agency

DOD: Department of Defense

DOE: Department of Energy

ICP-AES: Inductively Coupled Plasma-Atomic Emission Spectroscopy

IDA: Intensified Diode Array

LIBS: Laser-Induced Breakdown Spectroscopy

SOW: Statement of Work in the contract, which defines the tasks and the scope of work to be performed. 


\section{TABLE OF CONTENTS}

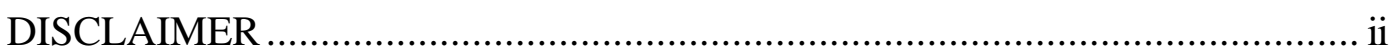

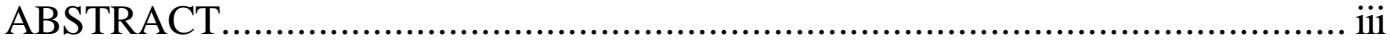

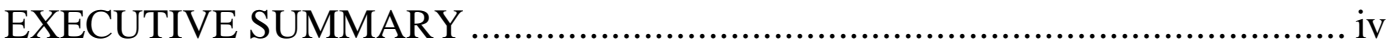

DEFINITION OF TERMS AND ABBREVIATIONS ....................................... vii

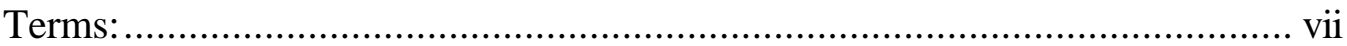

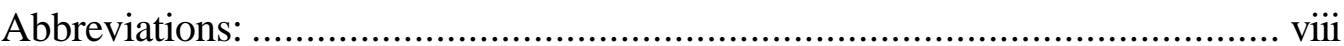

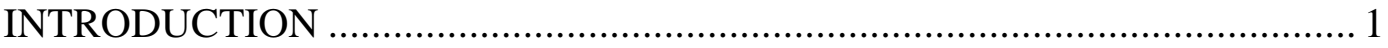

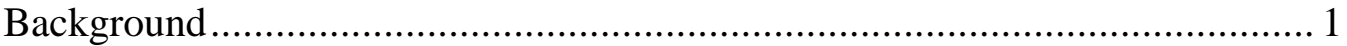

Tasks to Be Performed (from the SOW and Modification) ................................ 3

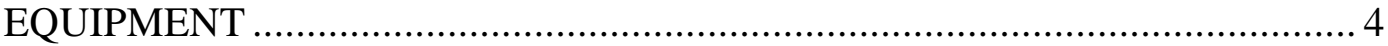

Gas Simulator Assembly and Calibration...................................................... 4

LIBS Equipment Assembly and Characterization ........................................... 8

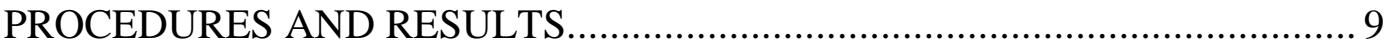

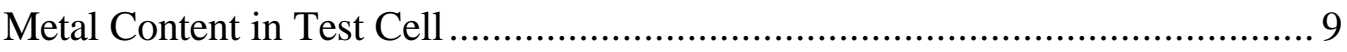

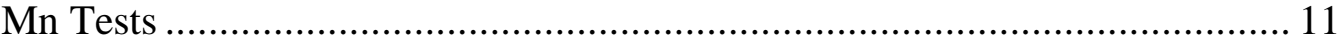

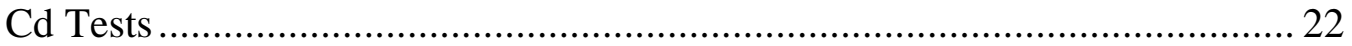

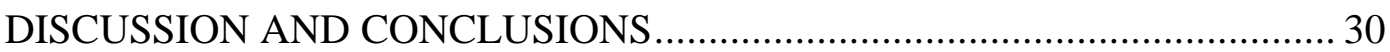

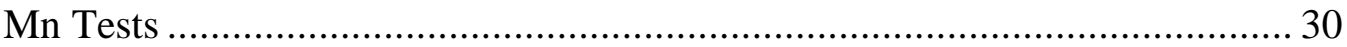

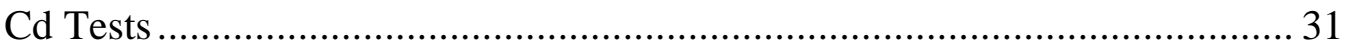

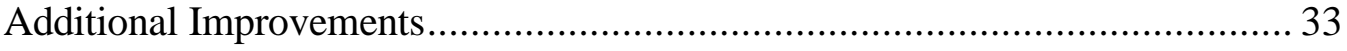

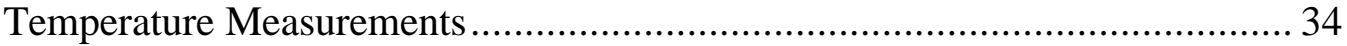

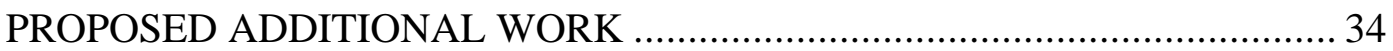


Automated Spectral Analysis and Self-Calibration.................................... 34

Particle Size Biasing .................................................................................. 35

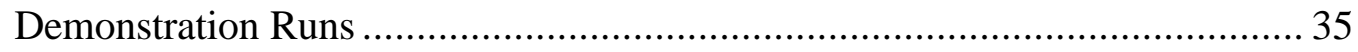

COLLABORATIONS AND PRESENTATIONS ...................................... 37

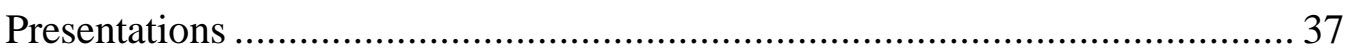

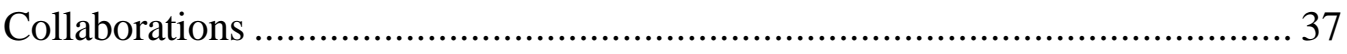

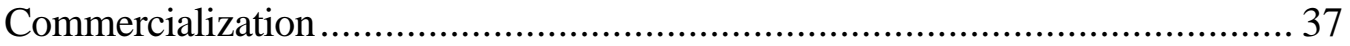

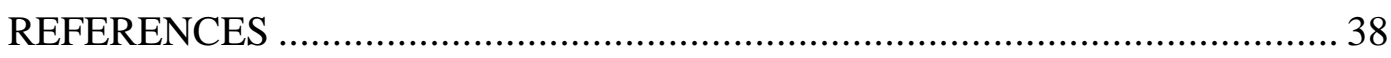




\section{INTRODUCTION}

\section{Background}

The DOE is planning to utilize thermal treatment facilities(rotary kilns, plasma torches, vitrification plants, etc.) to dispose of solid waste as part of its environmental restoration program. To assure compliance with the Clean Air Act (CAA) regarding emission of toxic metals in the off-gases of thermal treatment facilities, the conventional method is to characterize the waste feed followed by trial burns using EPA Method 29 to characterize the metal content in the off-gases. The use of a multi-metal continuous emission monitor (CEM) is a proposed alternative to the conventional method that would save an estimated six to nine billion dollars in waste feed characterization and trial burn costs. The multi-metal CEM alternative is currently not permitted by the CAA, but the EPA has indicated that when the technology has been proven to be reliable, certification of CEMs as an alternative would begin.

Two of the more promising methods of continuous toxic metal monitoring in offgases are an ICP-AES method and a laser-induced breakdown spectroscopy, LIBS, method. The ICP-AES method was developed at the China Lake Naval Facility and is now available from Thermo Jarrell-Ash. It performs continuous isokinetic sampling of the offgas followed by a flow reduction and dilution in argon to permit introduction into the torch of a standard ICP-AES.

The LIBS method involves focusing a pulsed laser beam directly into the off-gas, an in situ method, to form a micro-plasma spark, which is then analyzed using time-gated atomic emission spectroscopy. Application of this method as an off-gas CEM began at Sandia National Laboratory. This method has the advantage of directly sampling the gas, in situ, while not consuming any gases or chemicals nor generating any waste materials. Several improvements in the technique are needed before it will be useful as a reliable multi-metal CEM. One improvement that is needed is increasing the detection limits of some of the listed toxic metals. This is currently being developed at Sandia National Laboratory with DOD sponsorship. Another improvement that is needed before LIBS will 
be able to obtain EPA certification as a multi-metal CEM is calibration reliability within the regulatory requirements. These accuracy requirements have not been defined, but will likely be near $20 \%-30 \%$.

One difficulty with calibration of optical methods such as LIBS or ICP-AES, is that off-gas conditions and optical characteristics can affect the signal strength, so calibration must be continuously performed to correct for changing conditions. For LIBS, which is an in situ method, the calibration must be performed in the actual off-gas being monitored, which presents an additional difficulty. Once a reliable self-calibration method has been developed, the in situ LIBS CEM method will have the capability to maintain calibration when off-gas or optical conditions change, which is something the ICP-AES method has not addressed.

Characteristics of the laser-induced spark that affect the calibration are the plasma temperature, electron density, and spark size. The spark size and also optical alignment of the detector affect the total measured intensity of the laser spark. These effects can be corrected using an internal standard. For air-fed thermal treatment facilities, the best choice for an internal standard is nitrogen. For ICP and microwave plasmas, the temperature in typically not hot enough to form N(I) (ca. 5,000 K), but LIBS forms a much hotter plasma (ca. 10,000K - 15,000 K), sufficient to form atomic nitrogen, which can be used as an internal standard to correct calibration for changes in the total detected intensity.

In addition to total intensity, changes in the localized spark temperature can effect the calibration if atomic emission lines sensitive to the temperature (i.e., relatively high energy upper state emission lines) are used. The temperature also affects the ratio of ion to neutral atoms in the plasma, which can also affect the calibration. Thus the second aspect of LIBS self-calibration is to correct for any changes in the plasma temperature (and electron density) due to changing gas or laser characteristics. This is accomplished by analyzing the emission spectrum using two or more atomic emission lines from the same atomic species to determine the temperature and using the ratio of ion to neutral atom emission to determine the electron density, assuming a statistical thermal distribution in the 
plasma has been established. The localized thermal equilibrium requirement is estimated to occur in less than one microsecond after formation of the laser spark using a $10 \mathrm{~ns}$ laser pulse. ${ }^{1}$

The objective of the current stage of the funded work (Stage Four Development) is to test LIBS self-calibration procedures that correct changes in atomic emission line intensities resulting from changing gas or optical conditions. Toward this objective, a gas/aerosol generator system that allowed gas conditions in a LIBS test chamber to be changed was assembled and calibrated for the amount of metal in the gas flowing through the test cell. Two series of calibration curves were obtained, using Mn for one series and $\mathrm{Cd}$ for the other series.

After developing a self-calibration method, the next stage of development will be software for real-time data analysis that will include a database of emission spectra for the toxic metals and interfering elements and pattern recognition software with signal enhancement capabilities. Then a prototype design will be tested to demonstrate its capabilities at an operating thermal treatment facility. Also, prototype limitations, including detection limits and maximum particle size in the gas stream, will be characterized.

\section{Tasks to Be Performed (from the SOW and Modification)}

\section{Assemble Test/Prototype Equipment}

1. Design and assemble an aerosol and metal vapor apparatus capable of simulating the conditions of an off-gas. It shall be capable of generating calibrated, known amounts of metal aerosols or vapor in an optical cell. It shall also have the capability to control the temperature, pressure, water vapor content, and other gas constituents in the optical cell.

2. Assemble and optically align the equipment for a laboratory LIBS system, allowing efficient acquisition of laser spark emission spectra in the cell containing metal aerosols or vapor. 


\section{$\underline{\text { Test/Verify Calibration Concept }}$}

1. Using the apparatus and instrumentation assembled in the previous task, obtain time-resolved emission spectra of laser sparks generated for various gas conditions, laser energies, and detector collection efficiencies. The various gas conditions shall include dry aerosols, dry aerosols with water vapor, wet aerosol, the presence of easily ionizable elements in a dry aerosol, total gas pressure, and metal vapor. The carrier gas shall be nitrogen.

2. Calibrate the amount of metal in the gas during acquisition of these spectra.

3. Analyze the spectra to determine the localized plasma temperature and the relative intensity of atomic nitrogen emission.

4. Determine calibrated emission intensity of the metal, corrected for changing gas conditions.

5. Obtain calibration curves of the emission intensity, corrected for changing gas conditions, against the concentration of metal in the optical cell for the various gas conditions, laser energies, and detector sensitivities.

$\underline{Q A / Q C}$

1. Check for reproducibility by repeating some tests.

2. Use a second metal to perform the same self-calibration tests.

\section{EQUIPMENT}

\section{Gas Simulator Assembly and Calibration}

To test the self-calibration procedure for various gas conditions, different components were added or removed from an aerosol generator to create different types of aerosol conditions, which were then introduced into the optical test cell.

\section{A. Optical Cell}


The temperature-controlled optical cell used for all the LIBS calibration measurements is illustrated in Figure 1. It consists of a mini-conflat flange cube with 0.75 inch diameter tubes at the top and bottom for gas inlet and outlet.

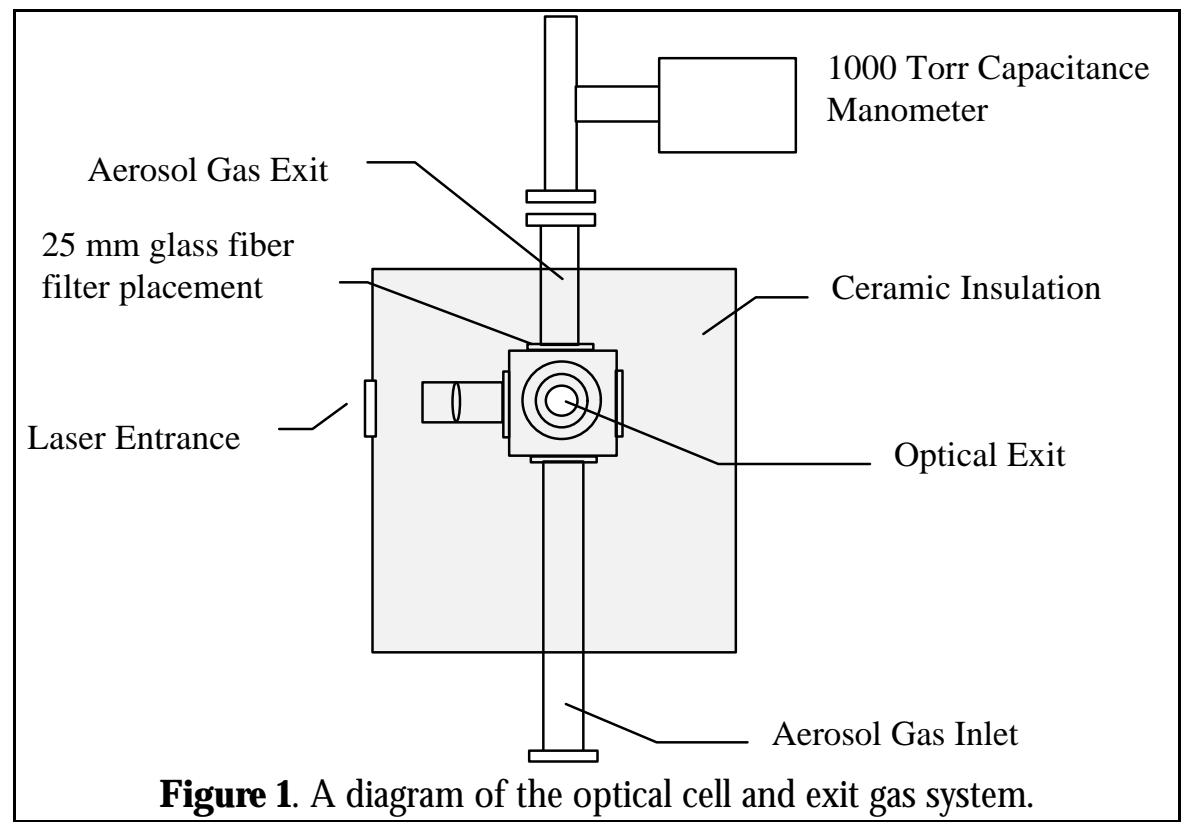

After exiting the cell, the gas flowed through a water scrubber before venting to the atmosphere. The gas flow was controlled using an MKS flow controller at the inlet of the nebulizer. The temperature was controlled using heat tape and thermocouples located on the cell and at the middle of the inlet tube, which was about $30 \mathrm{~cm}$ long.

For the laser entrance port, a $15 \mathrm{~mm}$ diameter, $25 \mathrm{~mm} \mathrm{f}$. 1 . lens was mounted in a metal tube. This was sealed to the test cell with an o-ring, which allowed small adjustment along the optical axis to position the spark in the center of the cell. For some tests a $50 \mathrm{~cm}$ f. 1. lens was used. A similar lens holder was used to hold the collection optics, which consisted of a $12 \mathrm{~mm}$ diameter, $17 \mathrm{~mm} \mathrm{f.} \mathrm{1.,} \mathrm{UV-grade} \mathrm{quartz} \mathrm{lens.} \mathrm{For} \mathrm{the} \mathrm{Mn} \mathrm{spectra} \mathrm{at}$ $260 \mathrm{~nm}$, a second UV-grade lens was used to image the spark onto the optical fiber bundle end with $1 \mathrm{X}$ magnification. For the Cd spectra at $220-230 \mathrm{~nm}$, the UV radiation was focused directly onto the entrance slit of the spectrograph. 


\section{B. Wet Aerosol}

To create wet aerosols, metal salt solution was aspirated using a nebulizer with dry nitrogen as the carrier gas controlled at a flow rate of 1.0 SLM. A spray chamber was used to preferentially remove the larger droplets. An illustration of the spray chamber used is shown in Figure 2.

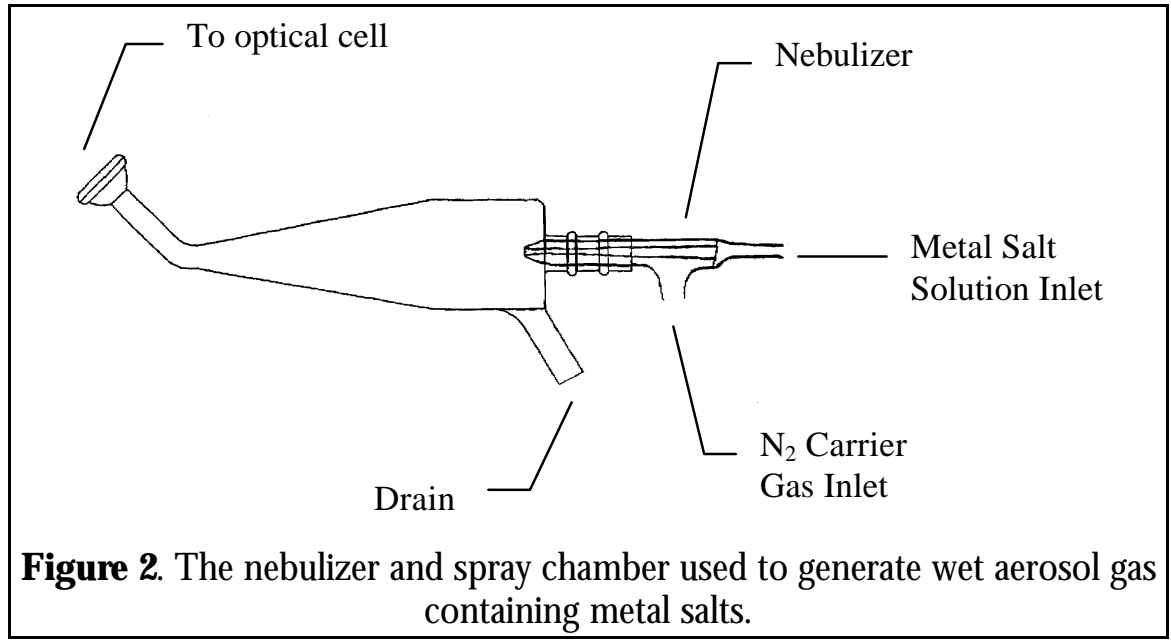

\section{Water Vapor}

A heated tube was used to separate metal salt in the aerosol from the water solvent. The nebulizer spray was directed into a $50 \mathrm{~cm}$ long, $18 \mathrm{~mm}$ diameter tube heated to $150^{\circ} \mathrm{C}$ using a tee joint with an o-ring adapter used to hold the nebulizer, as shown in Figure 3.

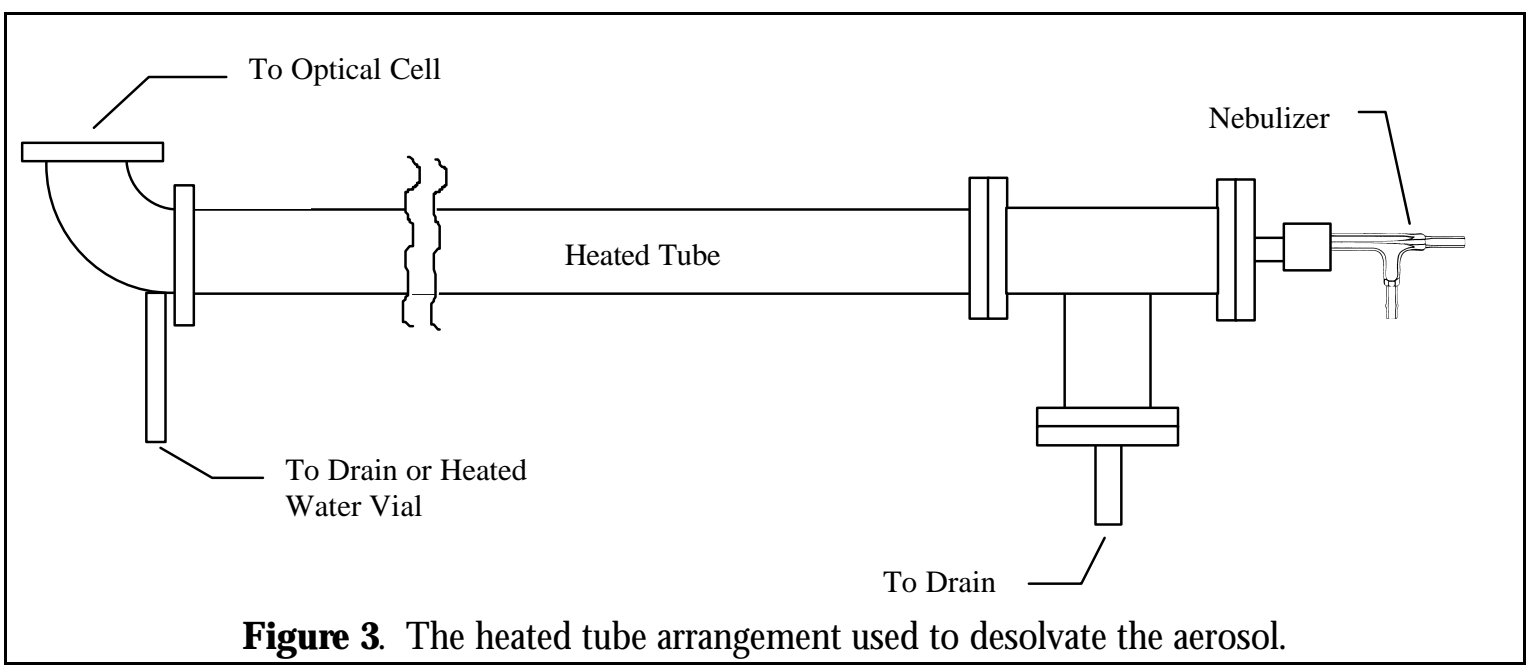

The side-arm of the tee joint with a $1 / 4$ inch Swaglok adapter was used to drain the 
nebulizer spray collecting on the tee-joint walls. During the manganese tests, the drain system was improved with the addition of a capillary tube inside the drain tube, which allowed collection in a sealed bottle. To prevent water vapor from condensing after exiting the desolvation tube, the optical cell was heated to $120^{\circ} \mathrm{C}$.

Two additional sets of data were taken with increased water vapor content in the gas by replacing the drain located after the heated tube with a $10 \mathrm{ml}$ cylinder of water heated to $45^{\circ} \mathrm{C}$ or $60^{\circ} \mathrm{C}$ to add nominally $15 \%$ or $20 \%$ water vapor in the carrier gas. One set of data was also taken with additional nitrogen at 10 SLM added to give a tenfold dilution at this port.

\section{Dry Metal Salt Aerosol}

To create a dry metal salt aerosol, a $600 \mathrm{~mm}$ long Claisen condenser was added after the desolvation tube and before the optical cell. The temperature in the condenser cooling outer jacket was maintained at $30^{\circ} \mathrm{C}$ using re-circulating water at ambient temperature. Additional data were taken with the condenser jacket cooled to $5^{\circ} \mathrm{C}$ using an ice bath to cool the re-circulating water.

\section{E. Water Content}

The water content values were estimated using vapor pressure tables and the observed rate of condensation on the condenser. The amount of water vapor in the gas flow using the heated tube was estimated to be about $10 \%$ (gas volume ratio) without the condenser, about $5 \%$ with the condenser at $30^{\circ} \mathrm{C}$, and about $2 \%$ with the condenser at $5^{\circ} \mathrm{C}$. When the cylinder of heated water is added after the heated tube, the water vapor added to the gas is estimated to about $20 \%$ at $65^{\circ} \mathrm{C}$ and about $15 \%$ at $45^{\circ} \mathrm{C}$. The numbers are intended to be used as guidelines rather than absolute numbers. 


\section{LIBS Equipment Assembly and Characterization}

\section{A. Laser}

To generate the spark, a Nd:YAG laser at $1.064 \mathrm{~nm}$ was used. It had a maximum pulse energy of $520 \mathrm{~mJ}$ with near Gaussian beam quality. The pulse energy was monitored continuously using a holographic beam splitter, which sent $1.01 \%$ of the total beam into a calibrated pyro-electric detector $(9.95 \mathrm{~V} / \mathrm{J})$. The remaining $99 \%$ of the laser pulse was focused into the LIBS off-gas cell using a $25 \mathrm{~mm} \mathrm{f}$. 1. quartz lens anti-reflective (AR) coated for $1.064 \mathrm{~nm}$. The laser energy was changed using the Q-switch delay. For all data taken, except the laser energy dependence study, the laser was operated at its maximum pulse energy, which was measured to be $520 \mathrm{~mJ}$. A slight drop in laser pulse energy (ca. $5 \%$ ) was seen during the first hour of operation, but then remained constant.

One calibration curve was obtained using a $50 \mathrm{~mm}$ focal length lens. For this longer focal length and lower f/\#, the position of the spark occurred before the focus, so to keep the spark centered in the cell, the lens was positioned with the focus past the center of the cell.

\section{B. Collection Optics}

To obtain emission spectra for Mn emission in the $260 \mathrm{~nm}$ region, a two meter long optical quartz fiber bundle was mounted at the entrance slit of the spectrometer using a dual lens design to match the $\mathrm{f} / \#$ of the spectrograph to the numerical aperture of the fiber with $1 \mathrm{X}$ magnification. The optical fiber bundle consists of ten UV grade quartz fibers 0.2 $\mathrm{mm}$ diameter $(0.22 \mathrm{~N}$. A.) formed into a $2 \mathrm{~mm} \times 0.2 \mathrm{~mm}$ slit at the spectrometer end and a $1 \mathrm{~mm}$ diameter circle mounted onto a standard SMA connector at the light collection end. The SMA connector allowed rapid connection to either the Hg lamp or to an optical emission collection lens system with SMA termination. The emission collection lens system consisted of a lens doublet with $\mathrm{f} / 2.5$ collection efficiency that matches the numerical aperture of the fiber with $1 \mathrm{X}$ magnification of the emission.

For the Cd emission in the $215 \mathrm{~nm}$ region, the optical fiber was found to have inadequate transmission at wavelengths below $240 \mathrm{~nm}$. For this reason, the spark image 
was focused directly onto the entrance slit of the spectrometer using two lens that matched the f/\# of the spectrometer and had collection efficiency of $f / 2.5$.

\section{Detector and Spectrometer}

The detector used for all measurements was a Princeton Instruments IY-1024 photo-diode array with 1024 elements ( $24 \mu \mathrm{m} \times 2 \mathrm{~mm}$ element size) and a $25 \mathrm{~mm}$ diameter intensifier optimized for blue response $(180 \mathrm{~nm}-800 \mathrm{~nm})$ with a minimum gate width of $50 \mathrm{~ns}$, a 14 bit resolution interface card, a controller for the diode array sweep rate, and a programmable intensifier gate controller. The diode array camera was mounted at the exit port of a $24 \mathrm{~cm}$ Czerny-Turner design spectrograph. Two gratings, $1200 / \mathrm{mm}$ and $600 / \mathrm{mm}$, were mounted on a turret in the spectrograph.

The diode array was aligned with respect to the spectrometer focus and optical plane by maximizing resolution of the $\mathrm{Hg}$ multiplet at $365.0 \mathrm{~nm}, 365.5 \mathrm{~nm}$, and $366.3 \mathrm{~nm}$ using a $25 \mu \mathrm{m}$ entrance slit width. The maximum resolution using the $1200 / \mathrm{mm}$ gating was found to be $0.3 \mathrm{~nm}$ FWHM, which is consistent with the manufacturer's quoted spatial resolution of $70 \mu \mathrm{m}$ for the intensifier. The entrance slit width was set to $50 \mu \mathrm{m}$ when acquiring the LIBS emission data.

Flat-field correction of a single spectral region and relative sensitivity of different spectral regions were obtained using calibrated emission lamps. For the region from $240 \mathrm{~nm}$ to $800 \mathrm{~nm}$, a Tungsten lamp was used. For the region from $190 \mathrm{~nm}$ to $400 \mathrm{~nm}$, a Deuterium lamp was used. The overlap between the Tungsten lamp and Deuterium lamp at $240 \mathrm{~nm}$ to $400 \mathrm{~nm}$ was used to scale the relative intensity of the two lamps, which allowed the entire region from $190 \mathrm{~nm}$ to $800 \mathrm{~nm}$ to be scaled to the same relative emission intensity.

\section{PROCEDURES AND RESULTS}

\section{Metal Content in Test Cell}

Determination of the weight of metal salt reaching the optical cell for each of the three apparatus set-ups was performed using $25 \mathrm{~mm}$ diameter, glass-fiber filter disks with 
$1 \mu \mathrm{m}$ particle size limit. A filter disk was placed across the cell exit flange fitting using an o-ring gasket and clamped in place using the exit tube flange, forcing the gas flow through the filter. The amount of metal collected was then determined by ICP-AES at an independent laboratory.

The flow resistance of the filter caused the solution uptake rate by the nebulizer to decrease about $15 \%$. Attempts were made to measure LIBS signals while a filter was in place, but the shock wave generated by the laser spark caused problems. Most attempts led to the filter bursting during the measurement. During one attempt in which the filter did not break, increased LIBS signal was observed. Analysis of this filter gave lower than normal Mn values, from which it was concluded that the laser spark shock wave was causing the Mn collected on the filter to be knocked loose, giving high signals and low collected sample. So, the filter collection was performed immediately before or after a series of data for one set of conditions were taken.

The results of the samples collected expressed in total metal collected on the filter are shown in Table 1. For the "vapor" conditions, using the set-up shown in Figure 3, three

Table 1 Results of independent analysis of total mass of metal analyte on the collection filters for a known amount of metal introduced into different aerosol gas set-ups. The numbers in italics have suspected errors (as discussed in the text) and were not used.

\begin{tabular}{|c|c|c|c|c|c|}
\hline $\begin{array}{c}\text { Sample } \\
\text { ID \# }\end{array}$ & $\begin{array}{c}\text { Gas } \\
\text { Conditions }\end{array}$ & $\begin{array}{c}\text { Solution } \\
\text { Conc. } \\
(\mathrm{ppm})\end{array}$ & $\begin{array}{c}\text { Total } \\
\text { Metal } \\
(\mu \mathrm{g})\end{array}$ & $\begin{array}{c}\text { Collected Metal } \\
(\mu \mathrm{g})\end{array}$ & Efficiency \\
\hline 4 & Wet & $100 \mathrm{Mn}$ & 1000 & 17.8 & $1.78 \%$ \\
\hline 6 & Vapor & $99 \mathrm{Mn}$ & 495 & 15 & $3.03 \%$ \\
\hline 7 & Vapor & $70 \mathrm{Mn}$ & 350 & 9.7 & $2.77 \%$ \\
\hline 8 & Vapor & $200 \mathrm{Mn}$ & 1000 & 34.4 & $3.44 \%$ \\
\hline 9 & Dry (5\%) & $100 \mathrm{Mn}$ & 500 & 4.4 & $0.88 \%$ \\
\hline 10 & Dry (5\%) & $100 \mathrm{Mn}$ & 500 & 8.3 & $1.66 \%$ \\
\hline 12 & Added Vapor $(15 \%)$ & $200 \mathrm{Mn}$ & 2000 & 47.4 & $2.37 \%$ \\
\hline 13 & Added Vapor $(20 \%)$ & $200 \mathrm{Mn}$ & 2000 & 45.6 & $2.28 \%$ \\
\hline 16 & Vapor & $100 \mathrm{Cd}$ & 1000 & 27.2 & $2.72 \%$ \\
\hline 19 & Dry $(2 \%)$ & $100 \mathrm{Cd}$ & 1000 & 18.7 & $2.02 \%$ \\
\hline 21 & Wet & $100 \mathrm{Cd}$ & 1000 & 15.6 & $1.56 \%$ \\
\hline 22 & Dry $(2 \%)$ & $100 \mathrm{Cd}$ & 1000 & 17.3 & $1.73 \%$ \\
\hline 23 & Wet & $100 \mathrm{Cd}$ & 1000 & 17.5 & $1.75 \%$ \\
\hline
\end{tabular}

measurements at different manganese aerosol solution concentrations indicate a somewhat higher efficiency for higher concentrations, but this is within the error of the measurement. 
The average of the values in Table 1 is $3.08 \%$ for manganese. The cadmium measurement for "vapor" conditions was a little lower, but consistent with the manganese

measurements. For the "dry" conditions, the efficiency of getting metal from the nebulizer to the cell was lower because of the addition of the condenser. Initial problems with leaks around the condenser joints are the reason for the low value of sample \# 9. The setup in which water vapor was added after the heated tube also lowered the efficiency of getting metal from the nebulizer to the cell.

Attempts were also made to perform a collection filter calibration when 10 SLM of nitrogen was added to the flow. The flow restriction of the filter for the additional flow caused the pressure in the system to increase significantly. This pressure was apparently higher than the 32 PSI used in the 1 SLM nitrogen flow used to aspirate solution into the nebulizer, and it had the effect of pushing solution out of the nebulizer and back into the source container, making calibration impossible.

\section{Mn Tests}

\section{Acquiring Spectra}

The $600 / \mathrm{mm}$ grating was used to obtain emission spectra spanning the region from $240 \mathrm{~nm}$ to $384 \mathrm{~nm}$ in a single laser pulse. This allowed the Mn(II) lines at $260 \mathrm{~nm}$ and 292 $\mathrm{nm}$ and the N(II) lines at $333 \mathrm{~nm}$ and $344 \mathrm{~nm}$ to be obtained simultaneously. Flat-field correction of the diode array response and spectrograph imaging onto the array was performed. The pulsed intensifier in the detector was set for a $250 \mathrm{~ns}$ gate width, and its delay time after the laser pulse was varied from $1 \mu \mathrm{s}$ to $10 \mu \mathrm{s}$. For the calibration tests, the delay was fixed at $1750 \mathrm{~ns}$, which was long enough to establish thermal equilibrium in the plasma and short enough to have useful N(II) emission strength. A typical spectrum is shown in Figure 4. 


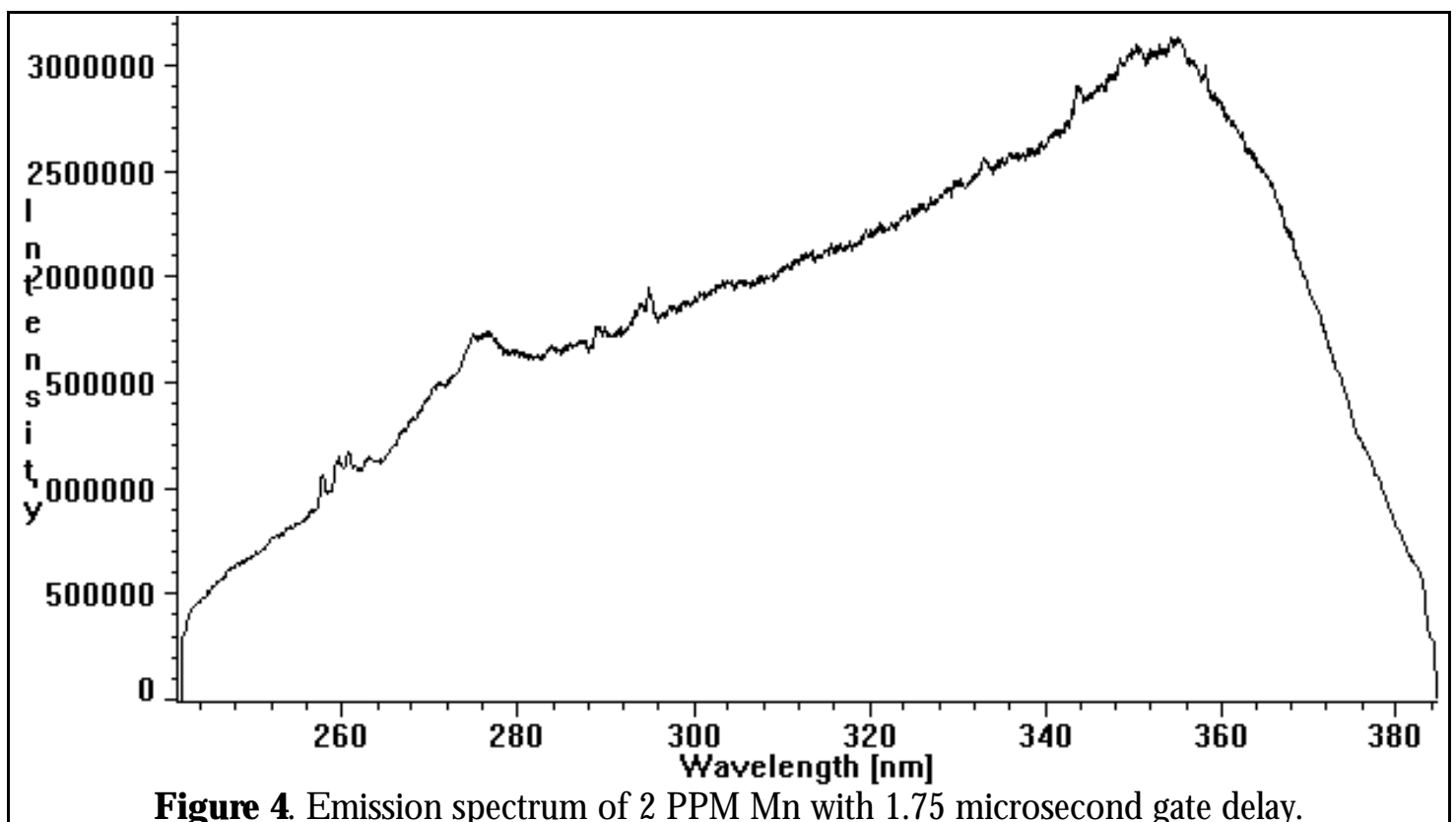

\section{Localized Thermal Equilibration Time}

To determine the plasma temperature, atomic emission line intensities of the two Mn(II) lines and the two N(II) lines in spectra such as Figure 4 were measured as areas under the line. The Mn emission multiplets at $260 \mathrm{~nm}$ and $293 \mathrm{~nm}$ were each composed of three lines originating from closely spaced upper energy states separated by less than two hundred wavenumbers. Since this energy spacing is much less than the energy separation between the $260 \mathrm{~nm}$ and $293 \mathrm{~nm}$ transition upper states, $\left(E_{2}-E_{1}\right)=4,900 \mathrm{~cm}^{-1}$, they were approximated as a single line.

The areas were determined by summing the count on individual pixels of the array detector over a defined range after subtracting the background. The plasma background was approximated as a straight line between the integration end points. The straight line approximation caused a "background area" for a spectrum of water aerosol with no manganese, which was the small area between the straight baseline and the curved background emission. This "background area" was treated as a zero concentration off-set and was subtracted it from all the manganese line areas obtained using a straight baseline.

The plasma temperature was determined using the ratio of intensities (areas) of the $\mathrm{N}(\mathrm{II})$ or Mn(II) lines originating from different energy levels and known transition 
probabilities, i.e., line strengths. ${ }^{2,3}$ For the manganese multiplet lines, the value used was the sum of individual transition probabilities, $g_{T} \cdot A_{T}=\sum_{i}\left(g_{i} \cdot A_{i}\right)$.

The equation used to determine the temperature was:

$$
\mathrm{T}=\left[\frac{\left(E_{2}-E_{1}\right)}{k}\right] \ln \left(\frac{I_{1} /\left(g_{1} \cdot A_{1}\right)}{I_{2} /\left(g_{2} \cdot A_{2}\right)}\right) .
$$

Initially, one thousand single pulse spectra were obtained to determine the temperature standard deviation. It was found to be entirely attributable to the standard deviation of the peak areas used to determine the temperature. So, 1000 shot averaged spectra were used for all temperature measurements.

The plasma temperature decay for Mn(II) and N(II) emission was measured by varying the detector delay time from $1 \mu \mathrm{s}$ to $10 \mu$ s for three different gas conditions. At delay times longer than $10 \mu \mathrm{s}$, the nitrogen temperature measurement was unreliable because of decreasing N(II) emission. The results are shown in Figure 5. They indicate that thermal equilibrium between $\mathrm{N}$ (II) and $\mathrm{Mn}$ (II) takes about $2 \mu$ s to be established, with $\mathrm{N}(\mathrm{II})$ hotter at earlier times. The main difference between gas conditions is that the wet aerosol gas causes the spark temperature to cool somewhat faster.

From this, the shortest time delay that can be used while assured of localized thermal equilibrium is about $2 \mu \mathrm{s}$. To maximize the $\mathrm{N}$ (II) emission, this minimum delay time was used for the self-calibration tests. 

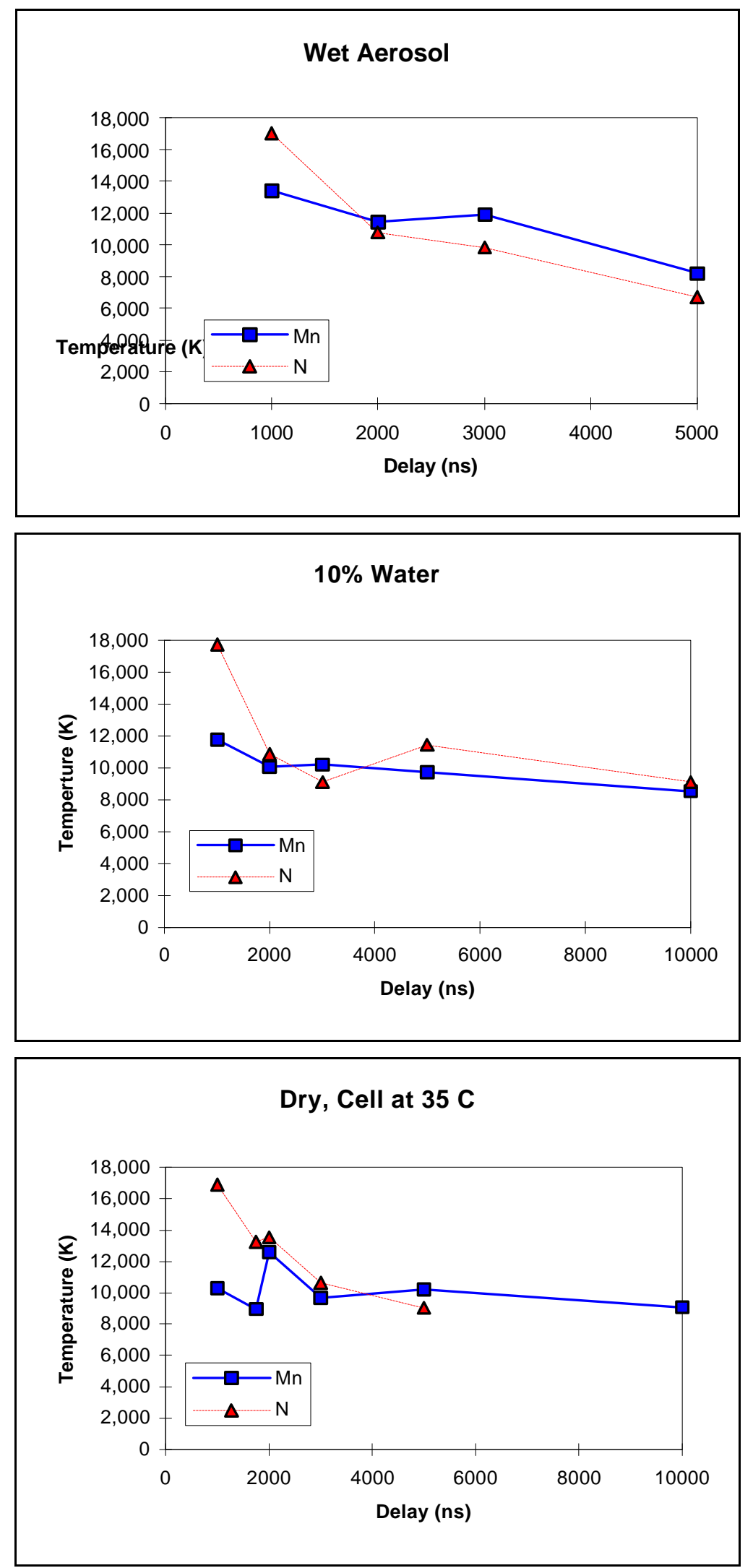

Figure 5. The plasma temperature determined from N(II) and Mn(II) emission as a function of delay time after the laser pulse. Results for three different gas conditions are shown. 


\section{Emission Calibration Curves}

A series of spectra were obtained for each set of conditions using different concentrations of manganese salt solution. The concentration of manganese in nitrogen gas in $\mathrm{ppm}(\mathrm{wt})$ was obtained from the solution concentration (ppm) times the solution uptake rate $(\mathrm{ml} / \mathrm{min})$ by the nebulizer times the percentage of manganese reaching the optical cell for the test conditions used (from Table 1) divided by the nitrogen flow rate (1.0 $\mathrm{SLM}=1.25 \mathrm{gm} / \mathrm{min}$ ). The uptake rate of solution by the nebulizer was measured for

each run (variation was generally less than a few percent). The rate was found to vary with the height of the solution bottle relative to the nebulizer height, so it was maintained at a fixed height for each of the arrangements of the apparatus (i.e., spray chamber, drying tube, and drying tube with condenser). Any water vapor contribution to the total pressure caused the nitrogen partial pressure and manganese concentration $\left(\mu \mathrm{g} / \mathrm{m}^{3}\right)$ to be less, but not the $\mathrm{ppm}(\mathrm{wt})$ manganese in nitrogen used for these calibration curves.

The Mn(II) emission intensity from the laser spark spectrum was plotted against the manganese in nitrogen concentration to obtain calibration curves. The calibration curves for each data set are presented in three manners: 1) using the uncorrected intensity of the $260 \mathrm{~nm}$ Mn line; 2) dividing the $260 \mathrm{~nm}$ Mn(II) line intensity by the $344 \mathrm{~nm}$ N(II) line intensity; 3) using the plasma temperature and line strengths to determine the ratio of total $\mathrm{Mn}$ (II) to total N(II) and total manganese to total nitrogen.

For all data sets the laser was run at its maximum pulse energy of $525 \mathrm{~mJ}$, except for the laser energy dependence data sets. For the optical and chemical speciation data sets the drying tube with no condenser was used (10\% water vapor).

\section{a) Uncorrected Single-Line}

The calibration curves shown in Figure 6 were obtained using the $260 \mathrm{~nm}$ multiplet and the straight line baseline method described earlier to subtract the background. It is seen that the gas and chemical conditions causes a factor of two or less change in calibration. The reproducibility of the $10 \%$ water curves on two different days in the second plot is about $\pm 15 \%$. Lowering the laser pulse energy or moving the optical fiber 
out of focus of the imaging collection optics causes the single line emission intensity to drop, which is not surprising.

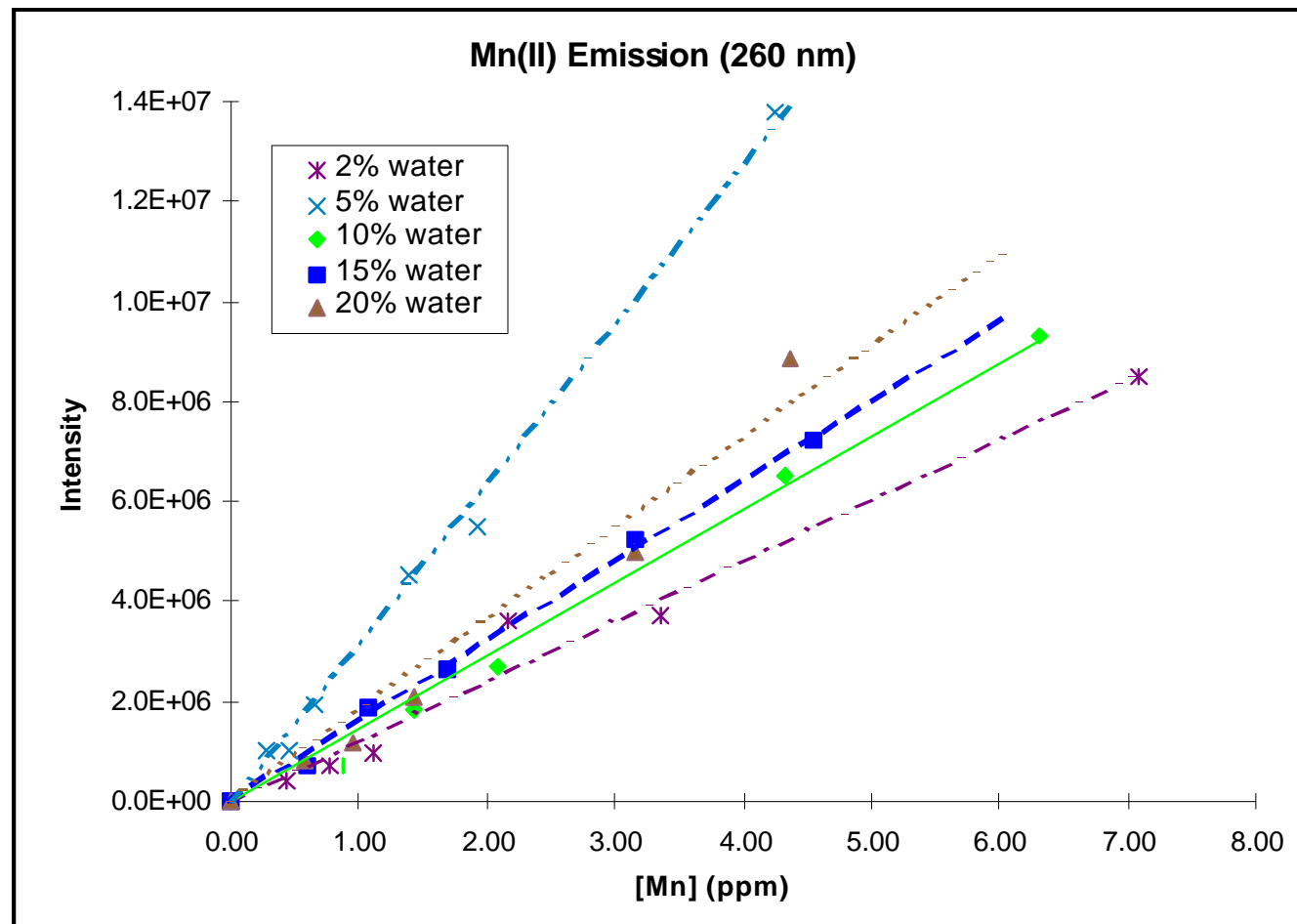

Figure 6 (a). Single line intensity calibration curves for various gas conditions.

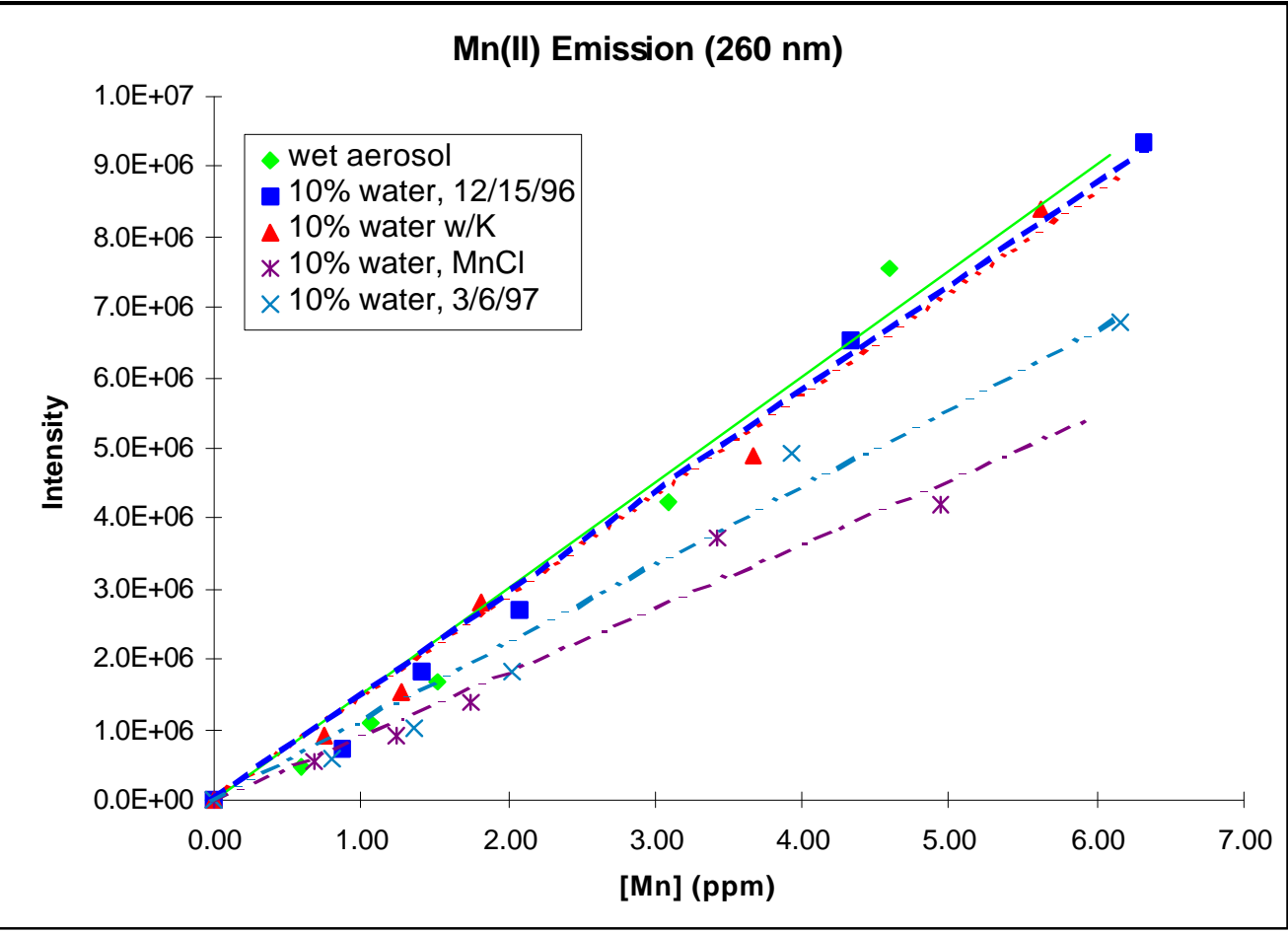

Figure 6 (b). Single line intensity calibration curves for various gas conditions. 


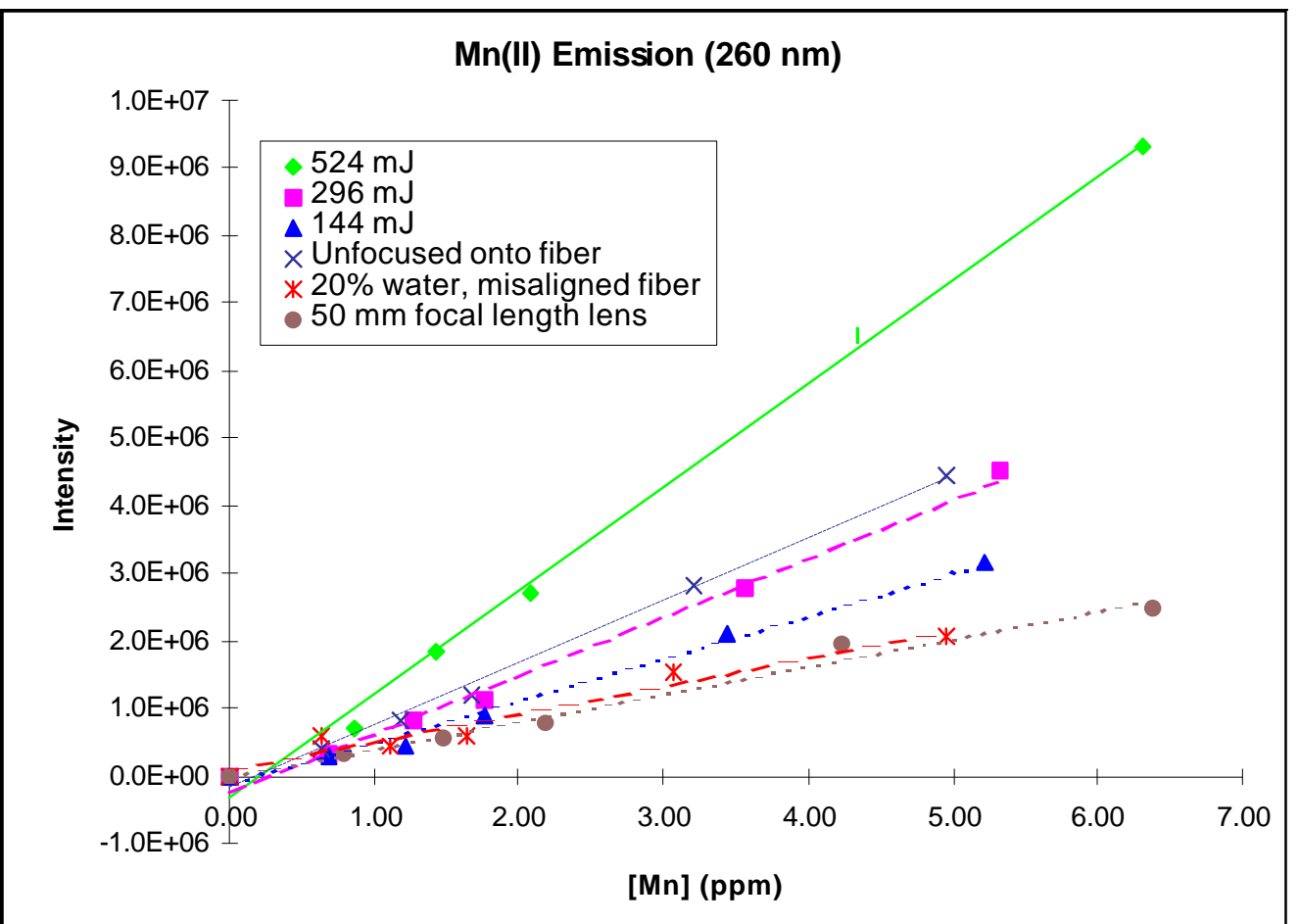

Figure 6 (c). Single line intensity calibration curves for various optical conditions.

\section{b) Single Line $[\mathrm{Mn}] /[\mathrm{N}]$}

The calibration curves in Figure 7 were obtained by plotting the intensity of the $260 \mathrm{~nm} \mathrm{Mn(II)} \mathrm{line} \mathrm{divided} \mathrm{by} \mathrm{the} \mathrm{intensity} \mathrm{of} 433 \mathrm{~nm}$ N(II) line from the same LIBS spectrum.

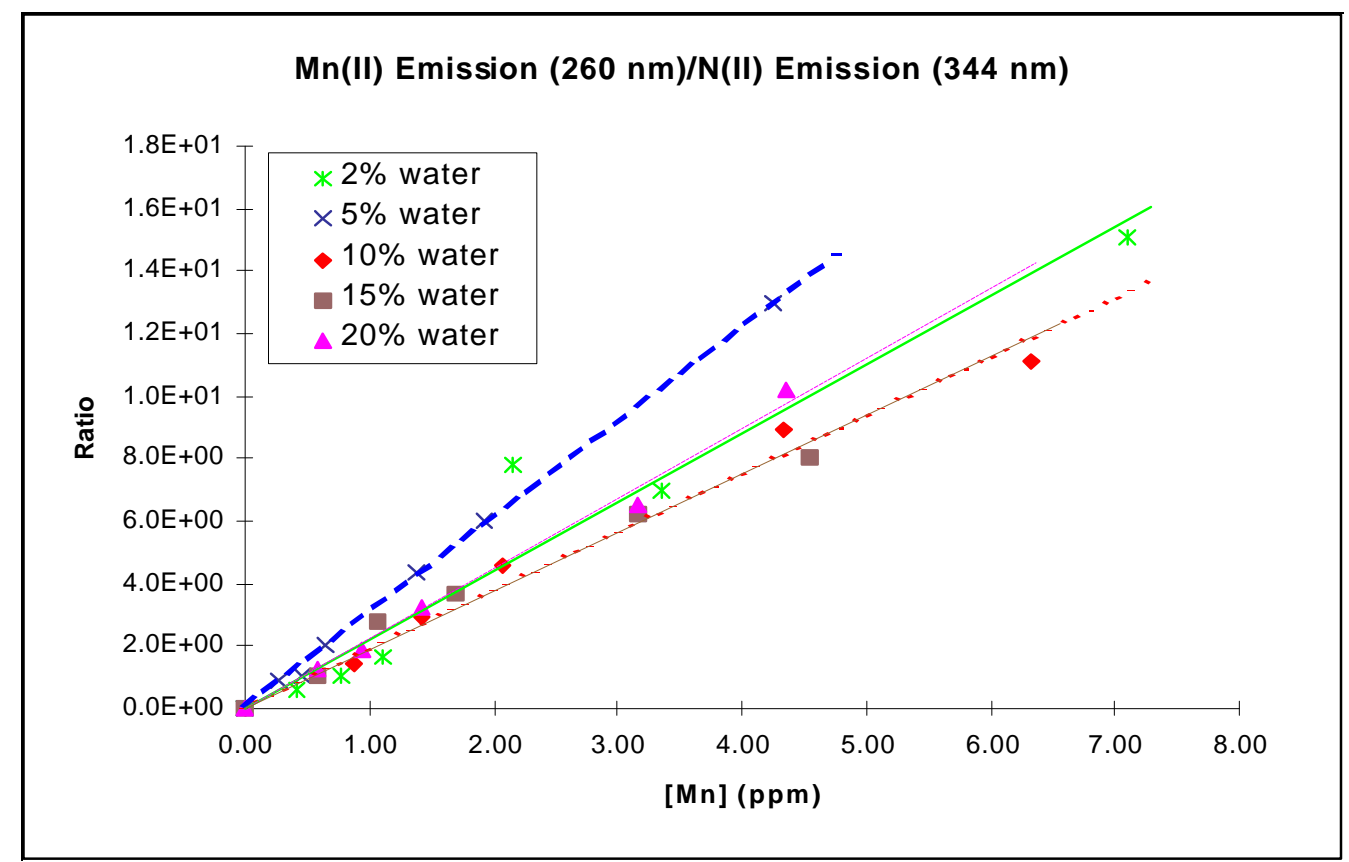

Figure 7 (a). Calibration curves for various gas conditions. 


\section{Mn(II) Emission (260 nm)/N(II) Emission (344 nm)}

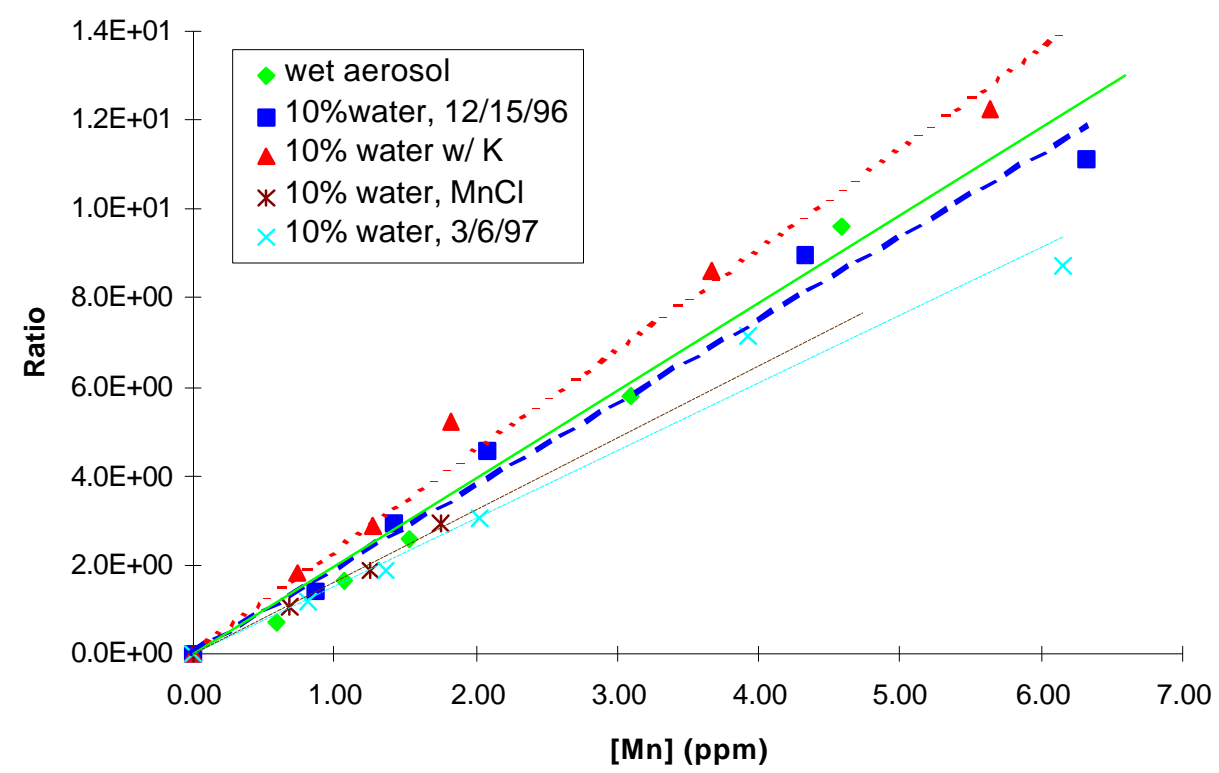

Figure 7 (b). Calibration curves for various gas conditions.

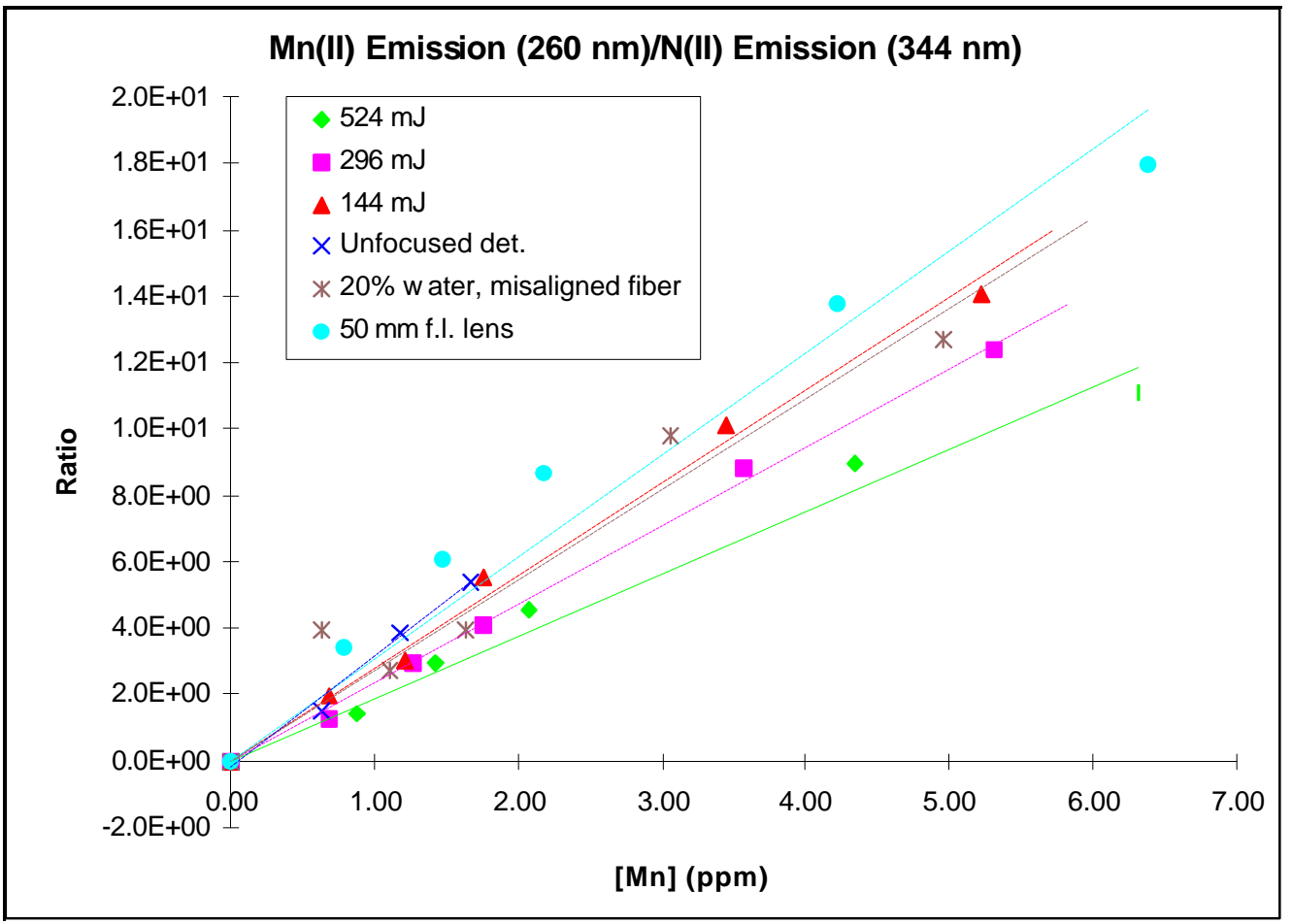

Figure 7 (c). Calibration curves for various optical conditions. 


\section{c) Ratio of Total [Mn]/[N]}

The temperatures obtained using the N(II) emission lines as described in a previous section were used to calculate the total number density of $[\mathrm{Mn}(\mathrm{II})]$ and $[\mathrm{N}(\mathrm{II})]$ using the formula

$$
[\mathrm{Mn}(\mathrm{II})]=\frac{I_{1} \cdot Q_{M n(I I)}}{a \cdot g_{1} \cdot A_{1} \cdot e^{-E_{1} / k \cdot T}},
$$

where $a$ is a sensitivity scaling factor and $Q$ is the statistical partition function.

The ratio of $[\mathrm{Mn}(\mathrm{II})] /[\mathrm{N}(\mathrm{II})]$ was calculated for each concentration in a calibration curve series. All the data points in the series were multiplied by the factor

$$
1.7 \cdot e^{136,010 \mathrm{~cm}^{-1} / k T}
$$

where the exponential energy term is the dissociation energy of $\mathrm{N}_{2}$ plus the ionization potential of $\mathrm{N}(\mathrm{I})$ minus the ionization potential of $\mathrm{Mn}(\mathrm{I})$, and the pre-exponential factor is the ratio of $\mathrm{Mn}(\mathrm{II})$ to $\mathrm{N}(\mathrm{II})$ partition functions times two $\mathrm{N}$ (II) ions per $\mathrm{N}_{2}$ molecule and was determined by an overall fit to all the Mn calibration curves.

This factor corrects for the temperature dependence of the ion to neutral atom ratio and the percentage of nitrogen dissociation in the plasma to give the concentration of manganese to nitrogen gas. (A preferable method of determining this factor would be to obtain the ratio of neutral atom emission to ion emission). In general the statistical partition functions are a slowly varying function of temperature. They are reported for $\mathrm{Mn}(\mathrm{II})$ and N(II) at temperatures up to $7300 \mathrm{~K},{ }^{4}$ but could not be found for the higher laser spark temperatures. They were assumed constant over the temperature range seen for the different conditions used for these tests.

Plasma temperatures measured for the laser spark $1.75 \mu$ s after the laser pulse for various conditions are listed in Table 2. These temperatures were used to calculate the correction factors described above. 
Table 2. Laser spark plasma temperatures.

\begin{tabular}{|c|c|}
\hline Gas Condition & Temperature (K) \\
\hline Wet & 12,100 \\
\hline $10 \%$ water, $\mathrm{KNO}_{3}$ & 11,300 \\
\hline $10 \%$ water $(12 / 5 / 96)$ & 13,200 \\
\hline $295 \mathrm{~mJ}$ & 11,700 \\
\hline $145 \mathrm{~mJ}$ & 10,800 \\
\hline Unfocused Detector & 13,500 \\
\hline $20 \%$ water, misaligned fiber & 15,200 \\
\hline $5 \%$ water & 13,800 \\
\hline $2 \%$ water & 15,600 \\
\hline $10 \%$ water, $\mathrm{MnCl}$ & 15,000 \\
\hline 50 mm focal length lens & 8,100 \\
\hline $10 \%$ water $(3 / 6 / 97)$ & 12,100 \\
\hline $15 \%$ water & 13,000 \\
\hline $20 \%$ water & 13,100 \\
\hline
\end{tabular}

Using this procedure, the concentration of manganese in nitrogen gas can be calculated, i.e. a self-calibration. Calibration curves using this self-calibration technique are shown in Figure 8.

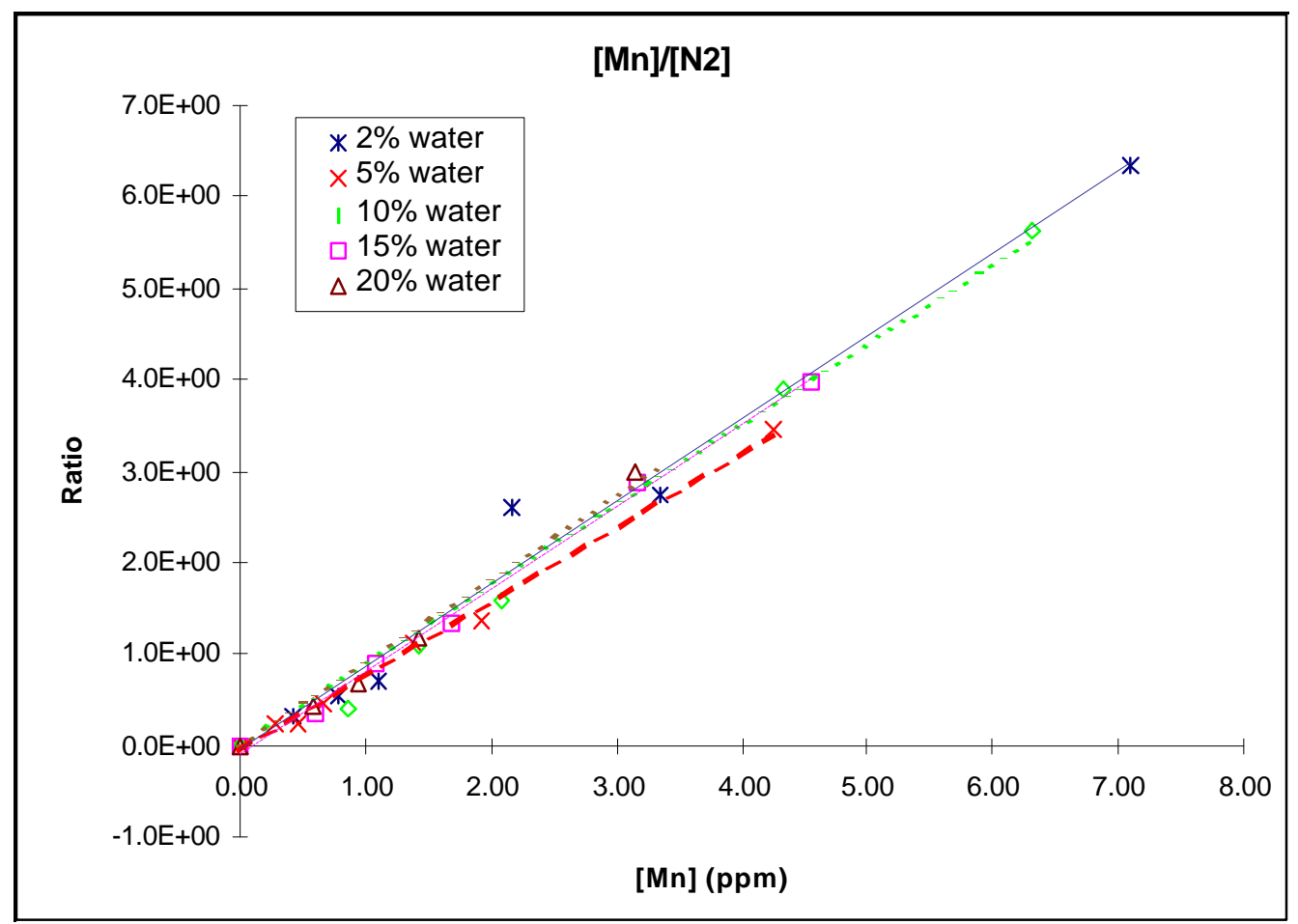

Figure 8 (a). Self-calibration curves for various gas conditions. 


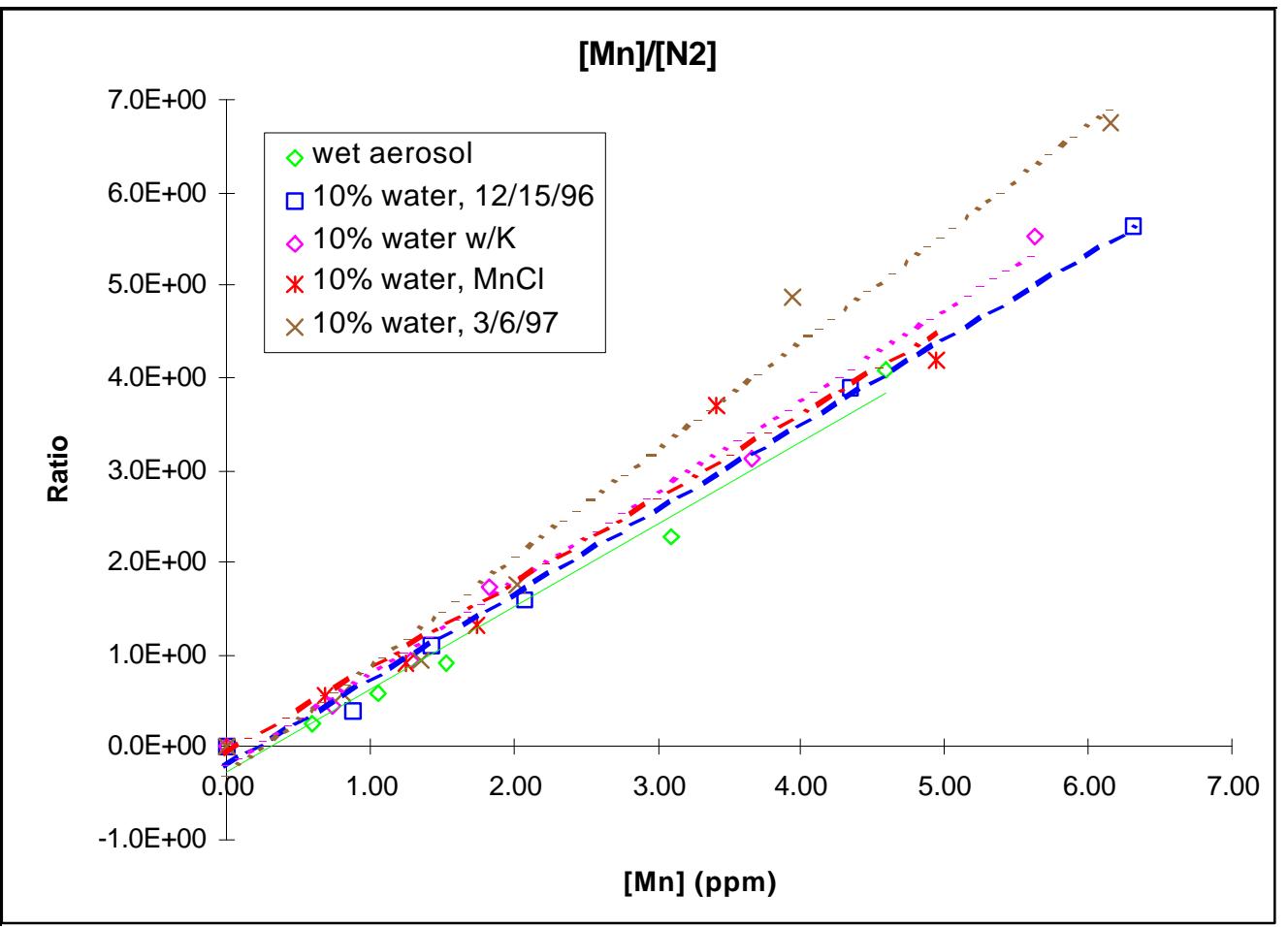

Figure 8 (b). Self-calibration curves for various gas conditions.

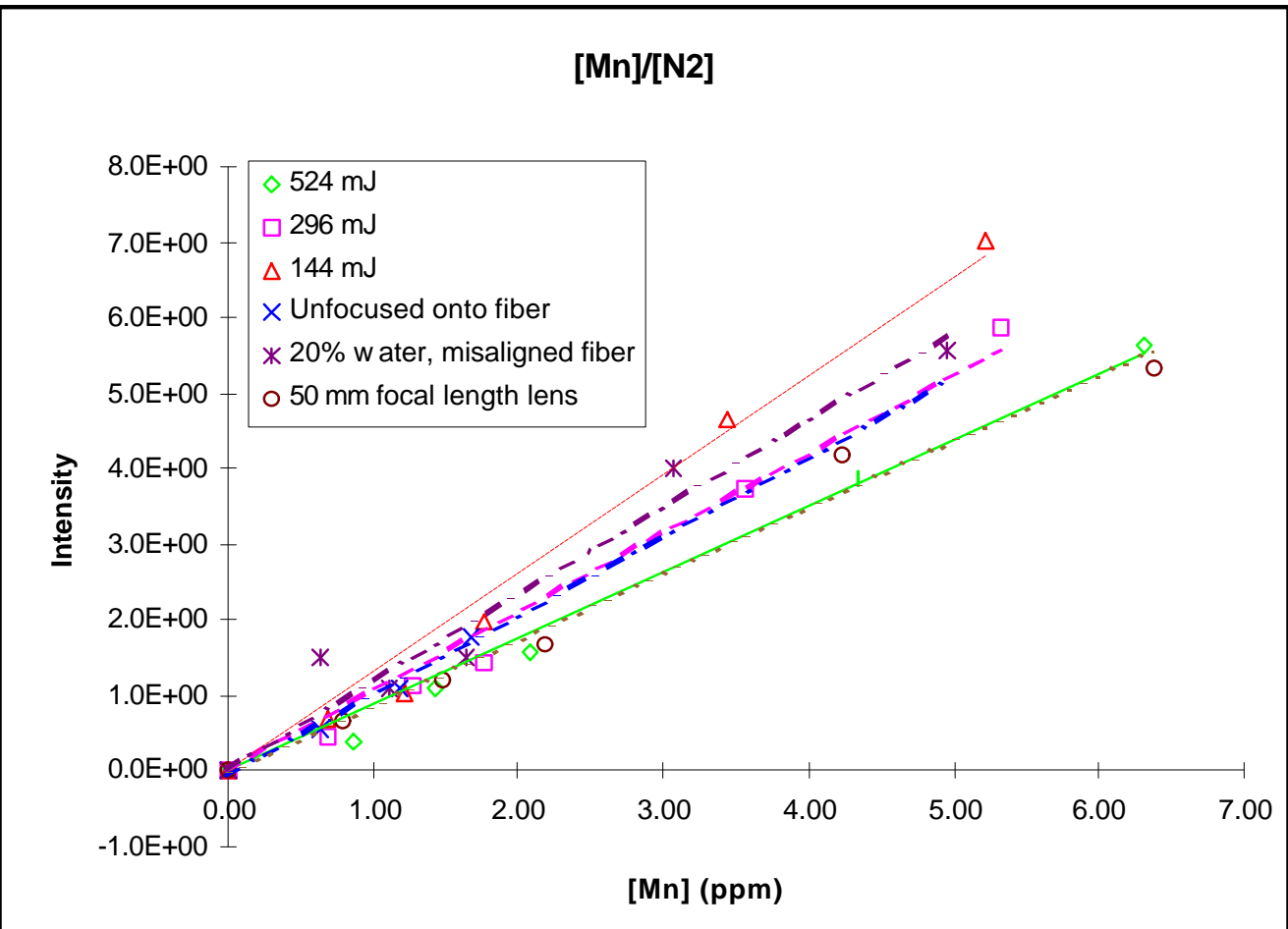

Figure 8 (c). Self-calibration curves for various optical conditions. 


\section{Cd Tests}

\section{Acquiring Spectra}

For the cadmium tests, the $1200 / \mathrm{mm}$ grating was used to obtain higher resolution and line height. $\mathrm{Cd}(\mathrm{II})$ lines at $214 \mathrm{~nm}$ and $226 \mathrm{~nm}$ and the $\mathrm{Cd}(\mathrm{I})$ line at $228 \mathrm{~nm}$ were obtained simultaneously. Several N(I) lines at $411 \mathrm{~nm}, 415 \mathrm{~nm}, 425 \mathrm{~nm}$ and $725 \mathrm{~nm}$ were used to determine the plasma temperature. They were measured by mechanically moving the grating to two different spectral regions under computer control. The spectrograph/detector was calibrated for wavelength and relative sensitivity at each of the three grating positions, and the information was stored as calibration files to be recalled when the spectrograph returned to that region. A relative sensitivity and flat-field correction was used to allow direct comparison of intensities from different spectral regions.

Spectra were obtained by performing 1000 shot averages. The detector intensifier was turned on for $1.0 \mu \mathrm{s}$, starting $10 \mu \mathrm{s}$ after the laser pulse. The longer delay maximized the $\mathrm{Cd}$ emission and $\mathrm{N}(\mathrm{I})$ emission, which occurs at $5-10 \mu$ s, while significantly reducing the broadband plasma emission. With the reduced broadband plasma emission, detector dark charge accumulation was the major source of background. This was subtracted using a 1000 shot averaged "dark charge" spectrum obtained by triggering the detector with no laser pulse. A new dark charge spectrum was acquired for each concentration series of data at each of the three wavelength regions. Typical spectra obtained for all three regions are shown in Figure 9. 

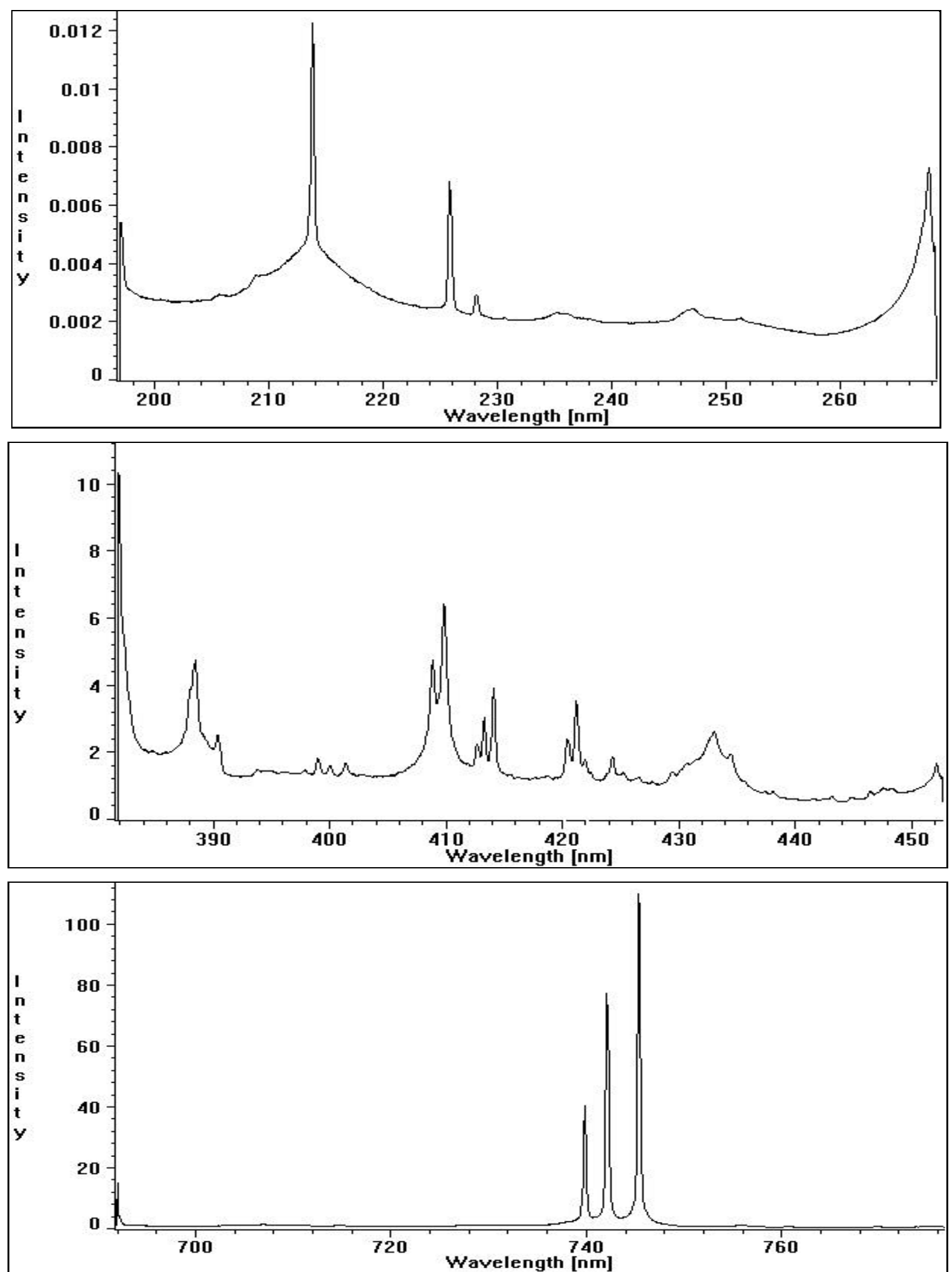

Figure 9. Three spectra obtained for $2 \mathrm{ppm} C d$ in nitrogen using a $10 \mu$ s detector delay, dark charge subtraction, and calibrated relative response. The increasing baseline at the ends of the spectra are an artifact of the flat-field correction. 


\section{$\underline{\text { Calibration Curves }}$}

Atomic emission line intensities were measured as areas in a manner similar to the $\mathrm{Mn}$ (II) calibration curves. Baselines were approximated as straight lines through the pixel range end points as with the $\mathrm{Mn}(\mathrm{II})$; however, a zero concentration, baseline subtraction was not needed. The overlapping $410 \mathrm{~nm}$ and $414 \mathrm{~nm} \mathrm{~N}(\mathrm{I})$ multiplets in the $435 \mathrm{~nm}$ spectra were separated using a single straight baseline that spanned the overlapping multiplets and then splitting the area into two parts corresponding to the $410 \mathrm{~nm}$ and 414 nm multiplet areas.

The amount of cadmium in the test cell was measured using the same method used for the manganese tests. The delivery efficiencies for the different gas aerosol set-ups are listed in Table 1.

The $\mathrm{Cd}(\mathrm{II})$ and $\mathrm{Cd}(\mathrm{I})$ emission intensities from the laser spark spectrum were plotted against the cadmium in nitrogen concentration to obtain calibration curves. The calibration curves for each data set are presented in four manners: 1) using the uncorrected intensity of the $214 \mathrm{~nm} \mathrm{Cd}(\mathrm{II})$ line; 2) using the uncorrected intensity of the $229 \mathrm{~nm} \mathrm{Cd}(\mathrm{I})$ line; 3 ) using nitrogen as an internal standard by taking the ratio of the Cd(II) $214 \mathrm{~nm}$ intensity to the intensity of the $\mathrm{N}(\mathrm{I})$ lines at $745 \mathrm{~nm}$; and 4) using the ratio of the total cadmium derived from both the $\mathrm{Cd}(\mathrm{II})$ lines at $214 \mathrm{~nm}$ and $216 \mathrm{~nm}$ and the $\mathrm{Cd}(\mathrm{I})$ line at $229 \mathrm{~nm}$ to the total nitrogen derived from the four N(I) lines using the plasma temperature.

For each method of generating calibration curves, the data are plotted in groups, one to demonstrate the reproducibility for various gas conditions and one for different laser powers and detector alignment. The laser was run at its maximum pulse energy of $525 \mathrm{~mJ}$, except for the laser pulse energy dependence data sets, which were taken at lower energy with $10 \%$ water vapor conditions.

\section{a) $214 \mathrm{~nm} \mathrm{Cd}(\mathrm{II})$ Line Intensity}

The calibration curves shown in Figure 10 were obtained using the $214 \mathrm{~nm} \mathrm{Cd(II)}$ emission line with the straight line baseline method described earlier to determine the background. It is seen that changing gas and chemical conditions causes a factor of two or less change in calibration. The reproducibility of the $10 \%$ water vapor, $2 \%$ water vapor, 
and condensed aerosols on two different days after complete disassembly and reassembly, shown in the second plot is about $\pm 6 \%$. Lowering the laser pulse energy or moving the optical fiber out of focus of the imaging collection optics causes the single line emission intensity to drop, as expected.

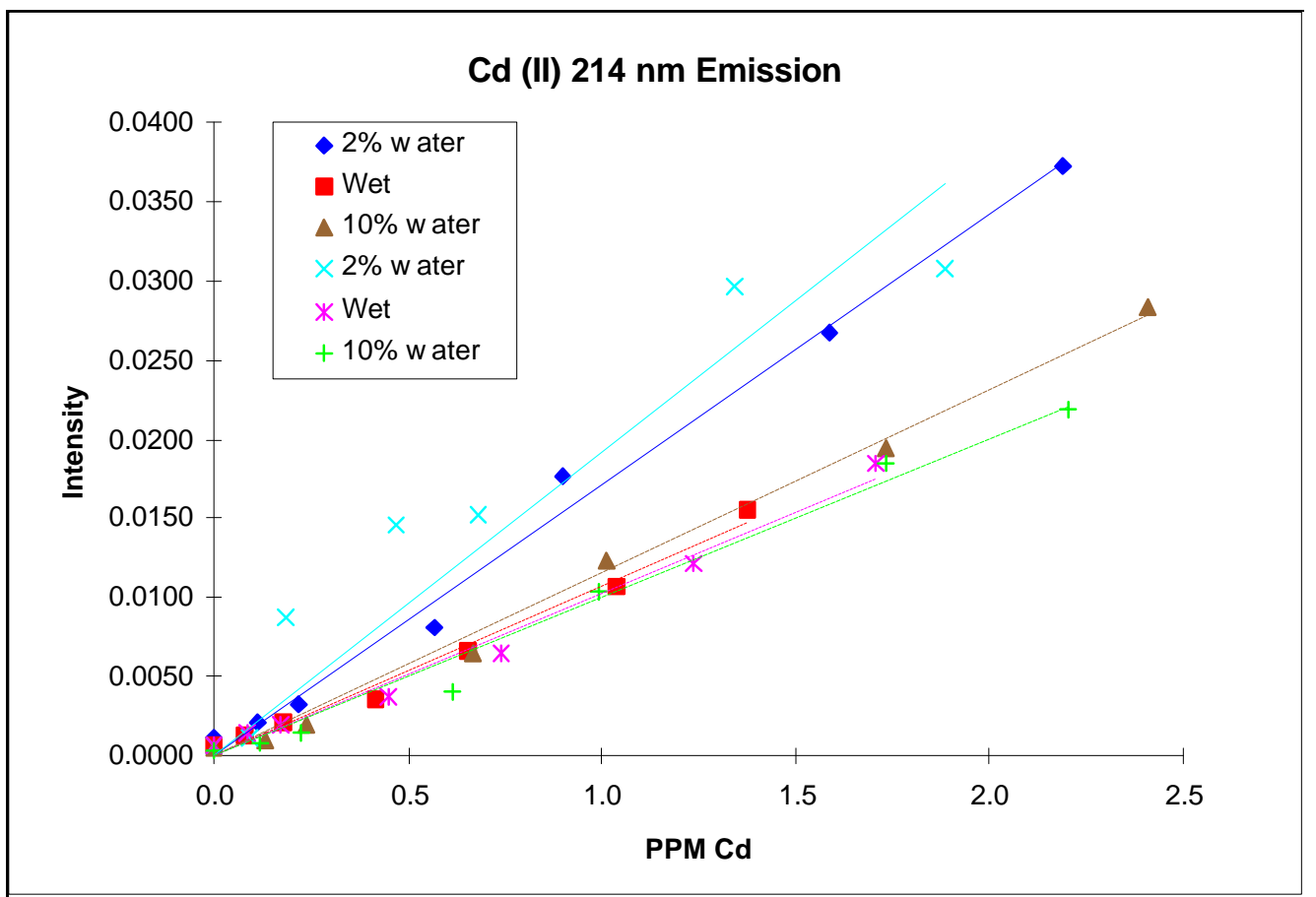

Figure 10 (a). Single emission line calibration curves for various gas conditions.

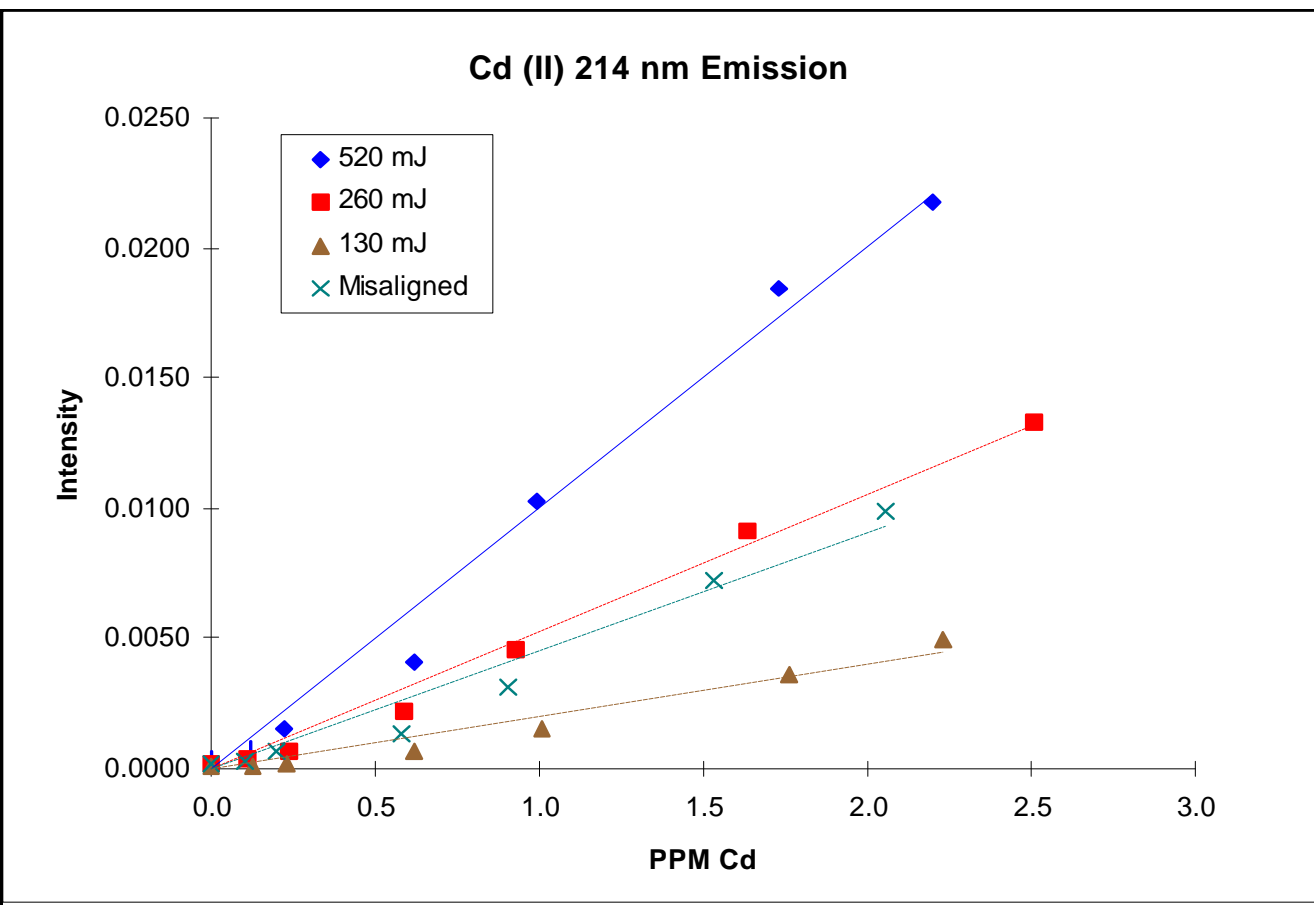

Figure 10 (b). Single emission line calibration curves for various optical conditions. 


\section{b) $229 \mathrm{~nm} \mathrm{Cd(I)} \mathrm{Line} \mathrm{Intensity}$}

The calibration curves shown in Figure 11 were obtained using the $229 \mathrm{~nm} \mathrm{Cd}(\mathrm{I})$ emission line in a manner analogous to Figure 10.. The results are similar, but with a lower reproducibility as expected for the lower $\mathrm{Cd}(\mathrm{I})$ emission strength.

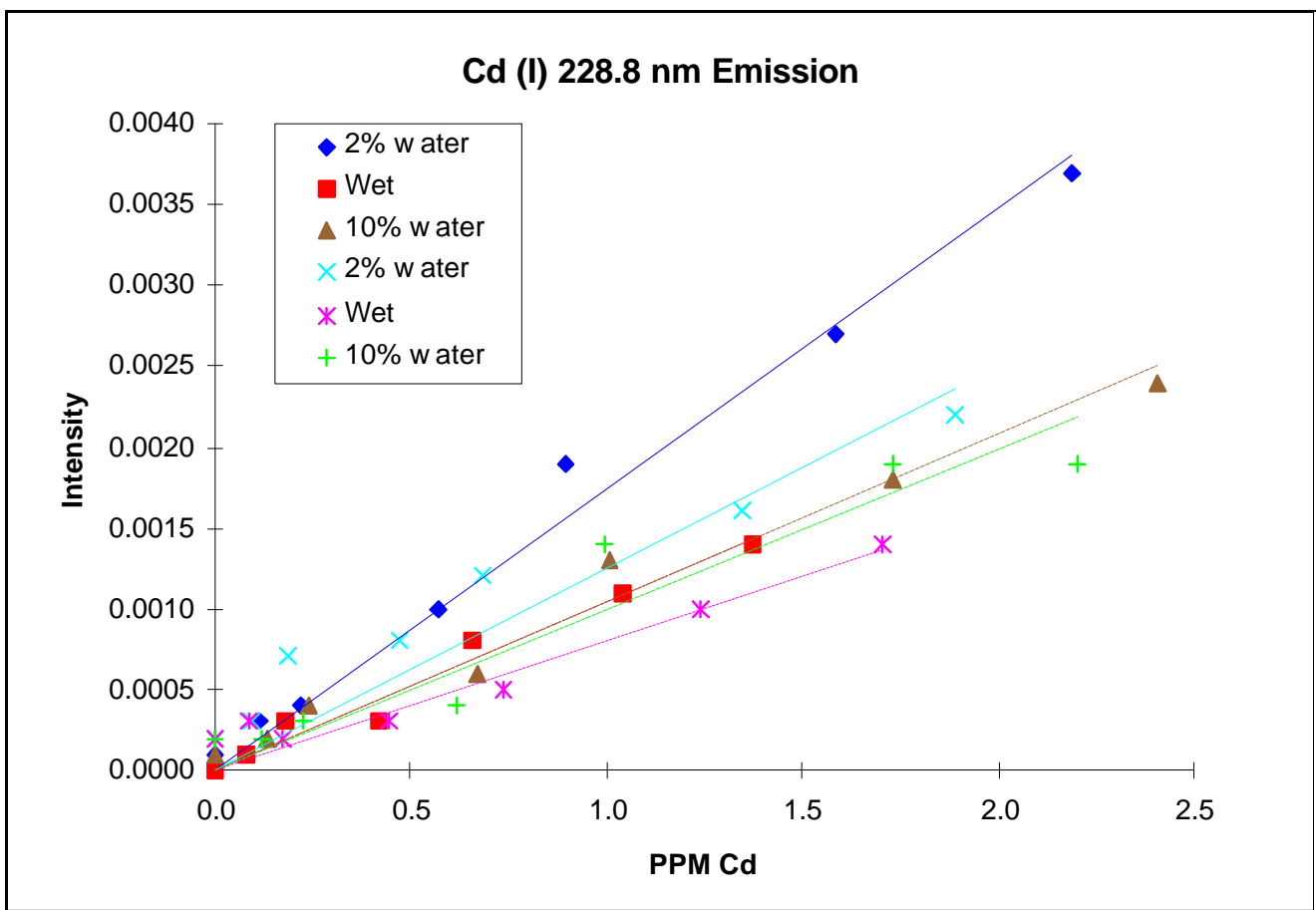

Figure 11 (a). Single emission line calibration curves for various conditions.

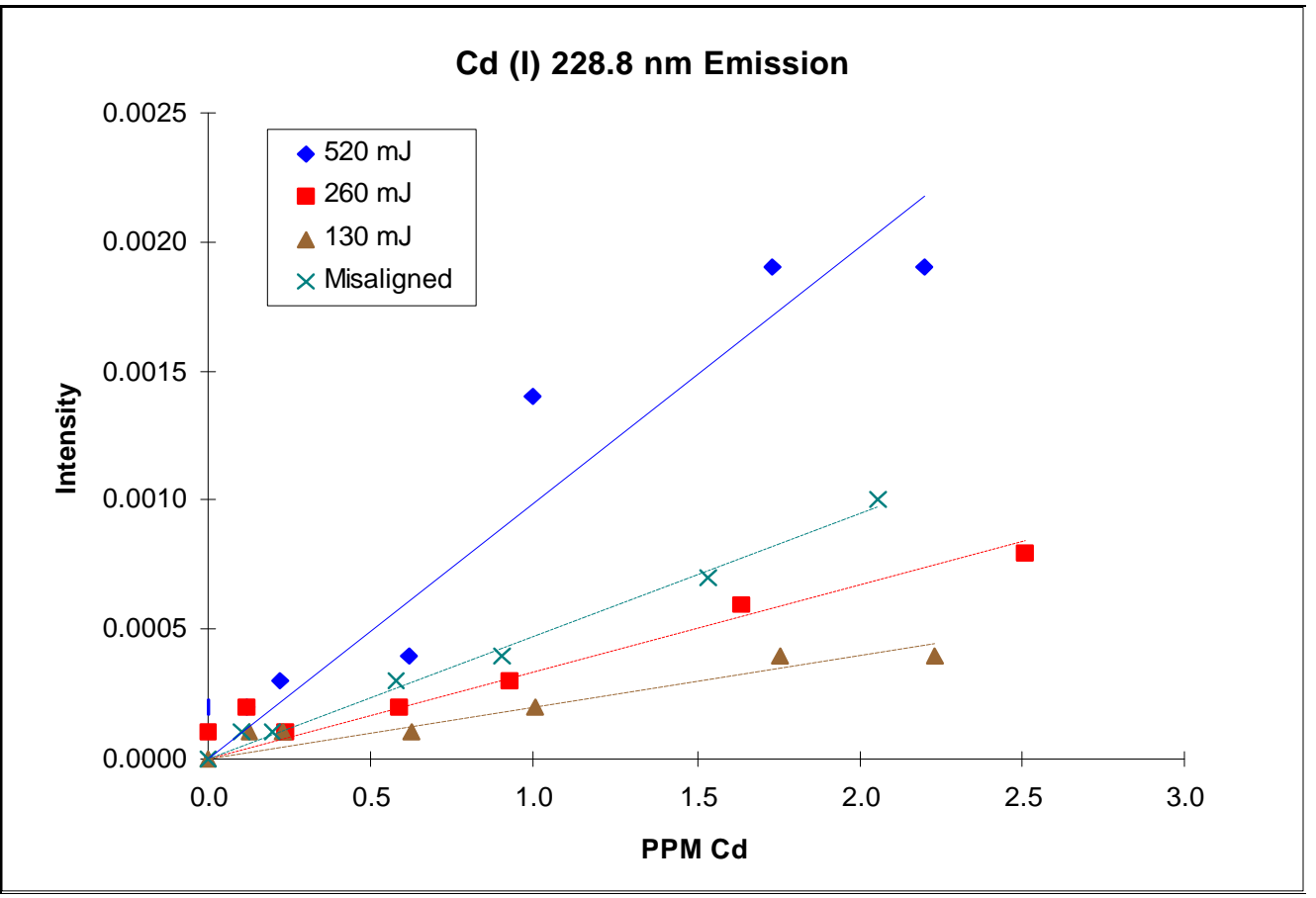

Figure 11 (b). Single emission line calibration curves for various conditions. 


\section{c) Ratio of $214 \mathrm{~nm} \mathrm{Cd}(I I) / 745 \mathrm{~nm} \mathrm{~N}(\mathrm{I})$}

The calibration curves in Figure 12 were obtained using the intensity of the $214 \mathrm{~nm}$ $\mathrm{Cd}$ (II) line divided by the intensity of the $745 \mathrm{~nm} \mathrm{~N}$ (I) line, obtained from different spectra.

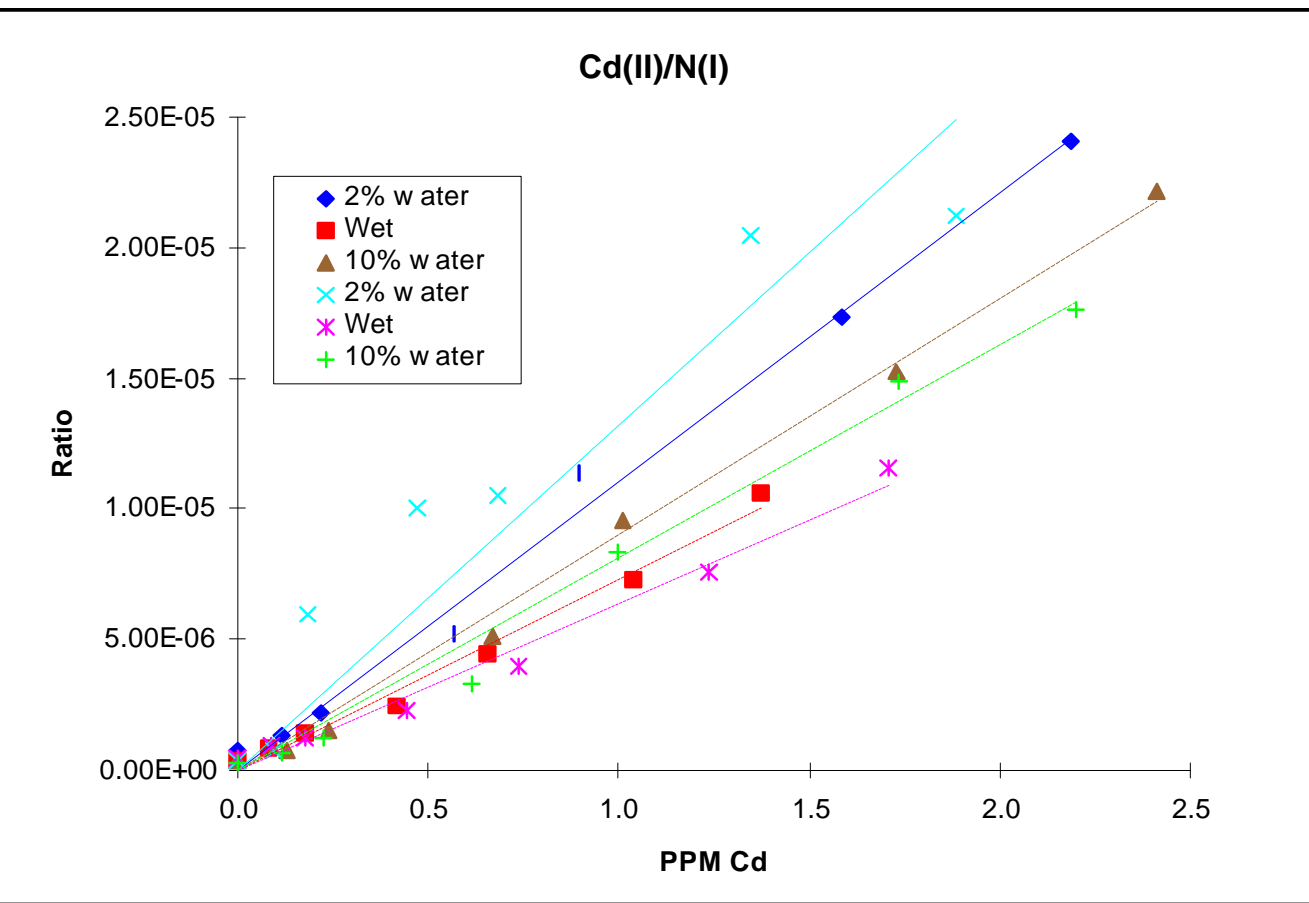

Figure 12 (a). Calibration curves obtained for various gas conditions.

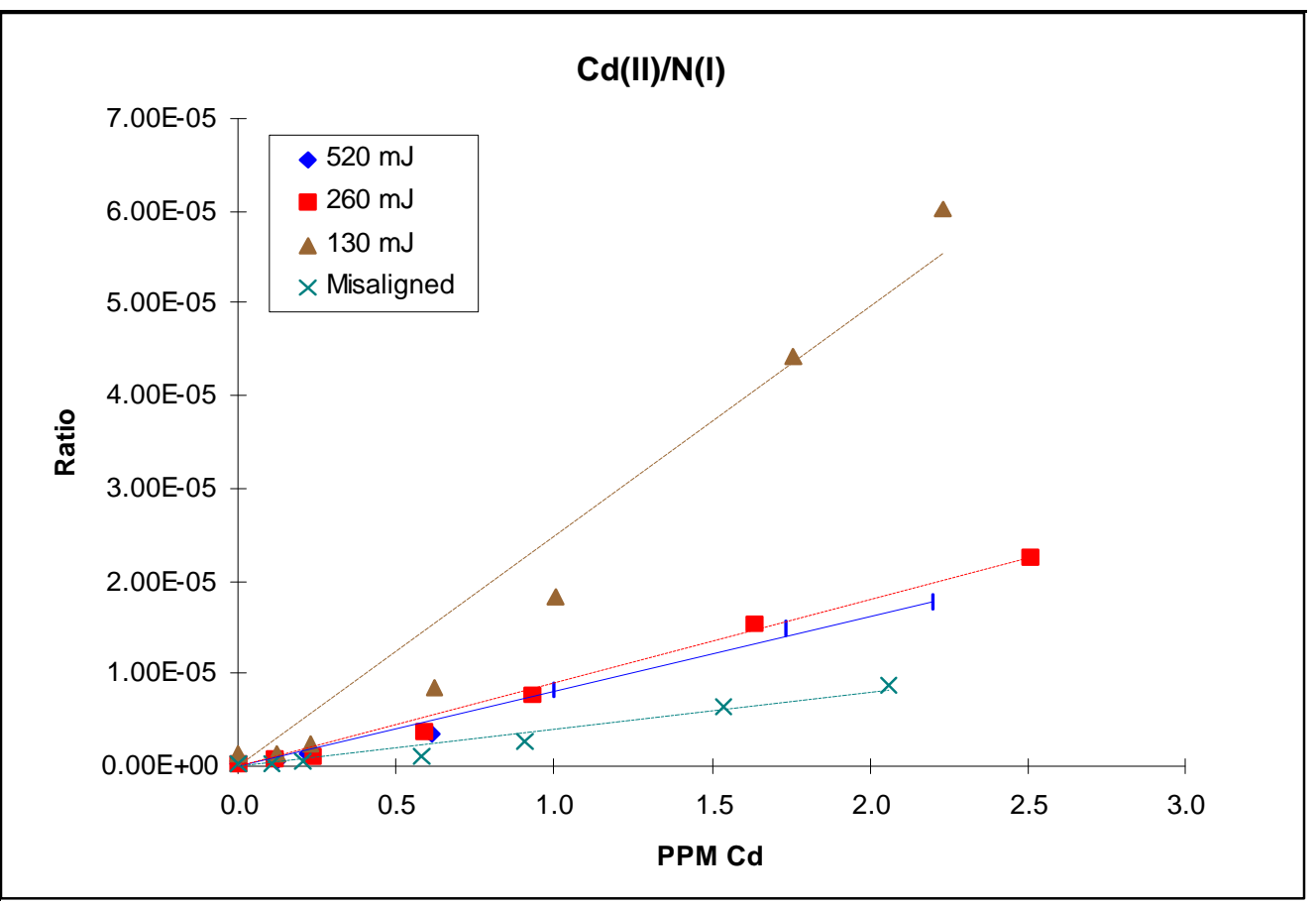

Figure 12 (b). Calibration curves obtained for various optical conditions. 


\section{d) Ratio of $[\mathrm{Cd}] /[\mathrm{N}]$}

The ratio of total $\mathrm{Cd}$ in nitrogen was determined in a manner similar to the procedure described for the manganese using the emission intensity, line strengths, upper state energy levels, and the plasma temperature. The temperature was determined using the four N(I) lines, which were used to generate an Arhennius plot. This involved plotting the natural logarithm of the line intensity (or multiplets originating from closely spaced upper energy levels) divided by the line strength against the upper state energy divided by the Boltzmann constant. The inverse of the slope of the linear regression line to the plot gives the temperature, and the intercept is proportional to the total N(I). The calculation was done in a spreadsheet by entering the four $\mathrm{N}(\mathrm{I})$ line intensities with the inverse slope and intercept calculated in the spreadsheet. A new line was used for each spectrum obtained.

Table 3. Laser spark plasma temperature at $10 \mu$ s delay used for the $\mathrm{Cd}$ tests for various conditions. The laser energy was $520 \mathrm{~mJ}$ unless noted otherwise.

\begin{tabular}{|c|c|c|}
\hline Gas/Laser Condition & Temperature (K) & $\begin{array}{c}\text { Estimated Standard } \\
\text { Deviation }(\mathrm{K})\end{array}$ \\
\hline Wet & 9410 & 230 \\
\hline Wet & 9230 & 90 \\
\hline $2 \%$ Water Vapor & 9770 & 70 \\
\hline $2 \%$ Water Vapor & 8900 & 270 \\
\hline $10 \%$ Water Vapor & 9310 & 150 \\
\hline $10 \%$ Water Vapor & 9020 & 210 \\
\hline $10 \%$ Water, 130 mJ & 7620 & 930 \\
\hline $10 \%$ Water, 260 mJ & 8400 & 180 \\
\hline Unaligned Optics & 9210 & 150 \\
\hline
\end{tabular}

The resulting temperatures for different conditions are listed in Table 3. This temperature measurement was performed at least three times for each set of conditions, which allowed a standard deviation of the temperature measurement to be estimated, which was also done in the spreadsheet.

The ratio of Cd(II) $214 \mathrm{~nm}$ emission to $\mathrm{Cd}(\mathrm{I}) 229 \mathrm{~nm}$ emission was used to determine the degree of ionization of $\mathrm{Cd}$ and $\mathrm{N}$. It was found that the Cd was $96 \%$ to $97 \%$ ionized to $\mathrm{Cd}(\mathrm{II})$ while $\mathrm{N}$ was $98 \%$ to $99 \%$ unionized as $\mathrm{N}(\mathrm{I})$. The total $\mathrm{Cd}$ used in the calibration curves included the $3 \%$ to $4 \% \mathrm{Cd}(\mathrm{II})$, but the total $\mathrm{N}$ did not include the $1 \%$ to $2 \% \mathrm{~N}(\mathrm{II})$. 
(As an note of interest, the electron density was about $1 \%$ of the $\mathrm{N}$ (II) density, so the electrons apparently diffuse rapidly from the spark volume). The ratio of these two numbers was multiplied by a factor 11,000 , which includes a factor for two nitrogen atoms per molecule and the ratio of partition functions, to obtain the calibration curves shown in Figure 13 . The one data set for $2 \%$ water vapor was the first data set obtained and shows a different temperature and the self-calibration slope is higher than the rest of curves. It is suspected that the spectrometer was accidentally bumped slightly after this run, causing the alignment of the lens image into the spectrometer and flat-field correction to change. The calibration also changes for lower energy and intentional optical mis-alignment, which are discussed in the next section.

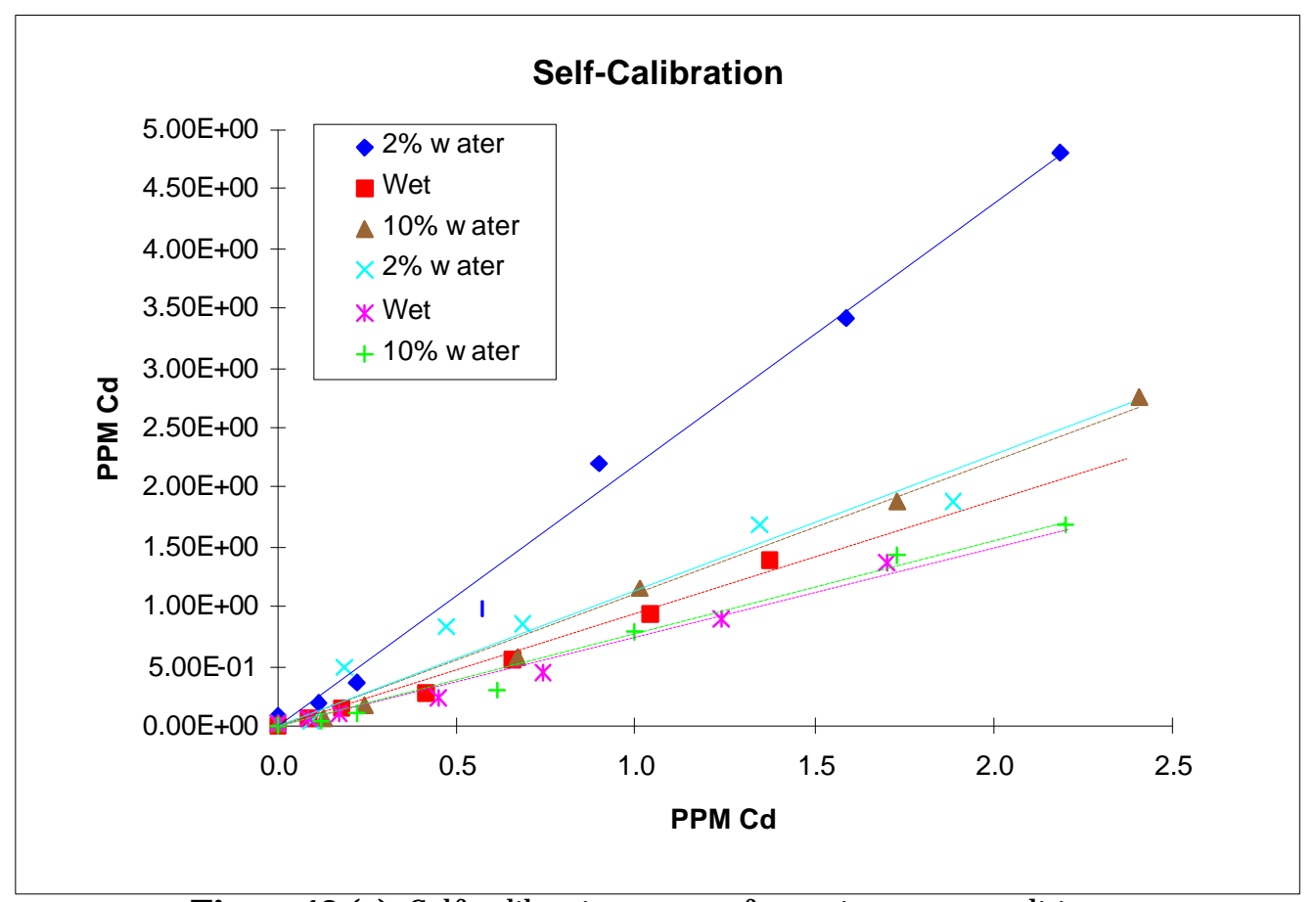

Figure 13 (a). Self-calibration curves for various gas conditions. 


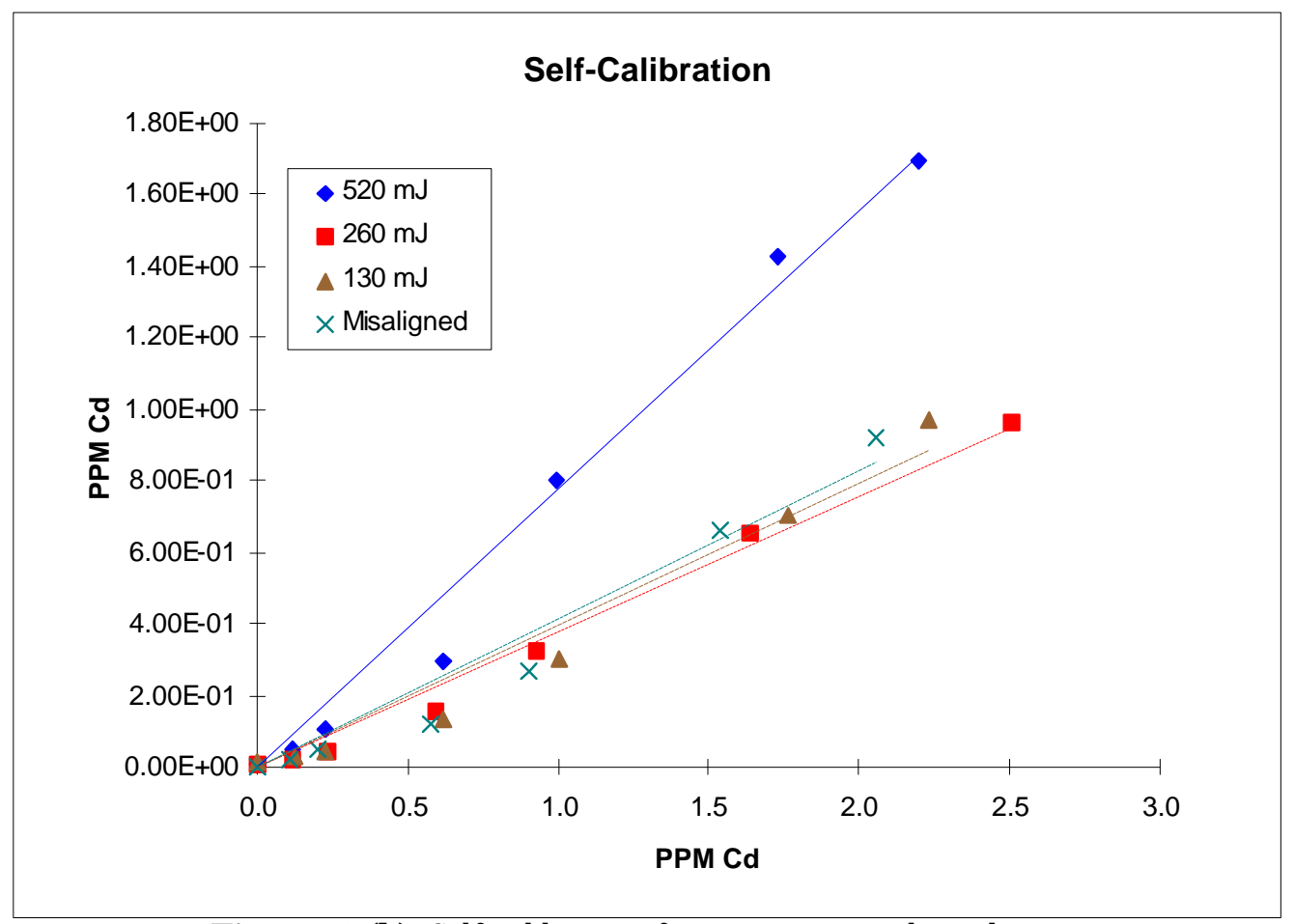

Figure 13 (b). Self-calibration for various optical conditions.

\section{DISCUSSION AND CONCLUSIONS}

The objective was to test LIBS self-calibration procedures that correct changes in atomic emission line intensities resulting from changing gas or optical conditions to maintain a constant calibration, independent of gas and optical conditions..

\section{$\underline{\text { Mn Tests }}$}

Calibration curves obtained for $10 \%$ water vapor using uncorrected Mn emission lines have slopes that differ by about $25 \%$ ( $\pm 12 \%$ error). This variation can be attributed to variation in the amount of metal reaching the cell or to changes in the optical alignment. Since laser alignment and optical fiber alignment were very stable in our bench laboratory system, the variation is attributed to uncertainty in the amount of metal in the cell. This is the limit to which the calibration correction procedures can be tested. This accuracy limit could be reduced by performing a collection filter measurement for every LIBS calibration curve (or even every data point on every calibration curve) to minimize this source of error. However, the $\pm 12 \%$ error is within acceptable limits for regulatory compliance. 
For the Mn calibration tests, the single line N(II) correction method appears to give similar results to the more involved self-calibration procedure, which requires using the temperature. The former set of calibration curves have a more uniform spread in "corrected" slope variation, while the latter self-calibration procedure does a better correction for more cases, with three or four exceptions. However, closer inspection of the two calibration curves for $10 \%$ water vapor using both calibration correcting methods gives some insight into the difference between the two methods. Using the nitrogen singleline correction method, the calibration slopes for different gas conditions are outside the range of the two $10 \%$ water calibration slopes. For the self-calibration method, the range of slopes for different gas conditions are within the range of the two $10 \%$ water calibration curve slopes. This suggests that uncertainty in the amount of metal in the cell may be the main reason for the variation in calibration slopes for the self-calibration procedure, and a more accurate knowledge of the amount of metal in the cell may reveal a lower variation in the calibration slope for different gas conditions. For the single-line correction method, other factors appear to be contributing to the variation in calibration slopes.

The variation in calibration slope for different optical conditions is also reduced using either correction method. However, the variation of corrected calibration curve slopes for both methods is outside the uncertainty of the metal concentration in the cell. The reason for this is not fully understood, but may be partly a result of the larger variation of calibration slopes for the uncorrected single-line calibration curves-requiring more correction. However, the decreased variation in calibration slope is still dramatic using either correction method.

\section{$\underline{\text { Cd Tests }}$}

The major intrinsic error in the self-calibration procedure for the manganese tests was measuring the required temperature accurately using the rapidly decreasing $\mathrm{N}(\mathrm{II})$ signal. For the Cd tests, N(I) emission lines were used to obtain the temperature measurement by moving the spectrograph grating to a different spectral emission region. Since the N(I) emission is longer lived than the N (II) emission, a longer delay time after the laser pulse 
was used for the detector gate. This allowed the plasma background emission to be reduced, giving increased signal-to-noise and sensitivity. For these tests the detection limits were not approached, since that was beyond the scope of the project, but the longer detector delay time allowed ten times lower metal levels to be used in the calibration curves with no additional effort.

Another weakness of the manganese tests was the need for a semi-empirical factor to correct for the temperature dependence of the electron density. This was required to correct for the degree of ionization of the nitrogen because N(II) was used. By using N(I) as the emission reference at a longer detector delay time not only is the background noise reduced, also correction for the electron density is not required since very little of the atomic nitrogen is ionized.

Using this method it can be seen in Figure 13 (a) that the calibration is held constant for varying gas conditions, within about $\pm 20 \%$, except for the one curve for $2 \%$ water. As mentioned earlier, this is strongly suspected to be a result of an accidental change in alignment of the spark image into the spectrograph, which changes the flat-field correction.

For some reason or reasons that are not understood, the ratio of $\mathrm{Cd}$ to $\mathrm{N}$ emission did not work as well at maintaining constant calibration as it did for the Mn tests. A partial explanation for this may be that the Mn tests used N(II) emission for which the temperature effect on the ion line emission was partially canceled by the temperature effect of $\mathrm{N}(\mathrm{I})$ ionization. When using $\mathrm{N}(\mathrm{I})$ emission as the correction factor, the temperature correction may be more important.

One possible complication from using a longer delay time is that the plasma temperature is low enough that dissociation of the very stable nitrogen molecule may not be complete. A simple statistical mechanical calculation ${ }^{5}$ predicts that less than complete dissociation occurs at about 11,000K (95\% dissociation), with a rapid change with temperature $(>30 \% / 1000 \mathrm{~K})$ occurring at $8000 \mathrm{~K}$. This effect is probably the explanation for the lower self-calibration slopes for the lower laser energy conditions, see Figure 13 (b), for which the measured temperatures were below 8,000K. This could be avoided 
to some extent by using a shorter detector delay time $(5 \mu \mathrm{s})$ to maintain plasma temperatures at $10,000 \mathrm{~K}$. When using the full laser energy this was not a significant problem.

Except for this problem at lower laser energy, the other main problem with the $\mathrm{Cd}$ tests was the use of a mounted lens to focus the emission onto the spectrograph rather than using an optical fiber. As mentioned already, this is suspected to be the reason that one of the $2 \%$ water calibration curves had a significantly higher slope than the other curves in Figure 13(a). This is also the reason the calibration curve for the purposely changed optical alignment calibration curve in Figure (b) is lower (It is not lower because of because of lower collected intensity). The optical alignment has such an effect because it shifts the flat-field and relative sensitivity calibration on the array detector.

Using an optical fiber avoids this problem because it is rigidly mounted onto the entrance of the spectrograph and is not affected by how the collected emission is launched into the fiber, which was demonstrated in the manganese tests. The reason an optical fiber was not used for the Cd tests was the far UV transmission is poor. A good compromise would be to use a short fiber $(50 \mathrm{~cm})$, but was not available in the short time required to perform the Cd tests.

The use of $\mathrm{Fe}$ (I) lines in the $350 \mathrm{~nm}$ region is another possible way to measure the temperature of the spark, since Fe is a very common element in waste streams.

\section{Additional Improvements}

In addition to using a short optical fiber other improvements can be made toward the objective of a high sensitivity and accurate multi-metal CEM.

One method to improve the signal-to-noise ratio in atomic emission spectroscopy is to increase the spectral resolution. Laser spark emission lines are relative broad at short delay times after the laser pulse, but sharpen as the plasma temperature and charge density drops. In this case higher spectral resolution will increase the peak high, giving a better signal-to-noise ration. 
The benefits of acquiring all the atomic emission lines on each laser pulse were demonstrated in the tests for manganese. However, this is generally not possible without sacrificing spectral resolution. One way to achieve maximum resolution and still acquire all the emission lines needed on each laser pulse would be to use an echelle spectrometer with an intensified CCD array detector. This also allows all metals to be measured simultaneously, which is an advantage if several metals are to be monitored continuously.

For the application of monitoring off-gases, iron emission is generally very strong since it is present in almost all types of solid waste. This emission is generally seen as an interference problem. However, these Fe lines can be used to measure the plasma temperature and electron density more accurately measured rather than using nitrogen emission lines. The iron emission cannot be used as an internal standard, since its concentration can vary, but only relative intensities are needed for temperature and electron density measurements. Selection of Fe lines for this purpose will begin soon.

Finally, work has begun on a proprietary method to accurately obtain line areas in LIBS regardless of the baseline shape or level. This is planned to be included in the software analysis program that is planned during the next stage of development.

\section{Temperature Measurements}

The temperature in the spark is known to be non-uniform. The temperature measured for the laser spark is spatially-averaged over the collection optics field-of-view. However, it can be shown that using this average temperature as a correction factor for the relative population of energy levels and degree of ionization is valid. The same can be said for the time-averaged temperature obtained when using a detector with response time slower than the rate at which the plasma is cooling.

\section{PROPOSED ADDITIONAL WORK}

\section{Automated Spectral Analysis and Self-Calibration}

Upon a decision to continue development, the next stage objective (Stage Five) will be to automate spectral analysis and the self-calibration procedure. This will require the 
development of automated spectral analysis software designed specifically for a LIBS CEM of off-gases using an atomic emission spectral database. The development of automated spectral analysis will be useful even if the self-calibration procedure is not included. Originally, creation of a database using literature values was the proposed first step. However, a small company in Gaithersburg, MD, AES, Inc. has such a database available with a search engine, and it is commercially available. After identifying atomic emission line positions in the acquired spectra, they would be compared to the database to identify metals present in the gas being analyzed. Sophisticated analysis including chemometrics, spectral pattern recognition, and possibly adaptive software that adjusts for changing conditions may be included along with the self-calibration software. It will be developed using MatLab toolboxes with the assistance of a consultant that is experienced in such development work.

\section{Particle Size Biasing}

Another task in the SOW is to determine the particle size that can be tolerated by the LIBS method before low biasing occurs. This is a well known effect caused by incomplete vaporization of larger particles in the laser focus. As a rule-of-thumb, a size limit of $20 \mu \mathrm{m}$ is used. This limit depends on the laser energy, the degree of particle loading, and other parameters. This size limit is generally above the size limit in thermal treatment off-gases required for regulatory compliance. For these reasons, this task is viewed as a lower priority than software development, and plans now are to spend most effort on those tasks.

\section{Demonstration Runs}

A final task is to perform a demonstration run at a DOE approved test site. Such a test run is occurring this September at the EPA research incinerator in Research Triangle Park, NC. Several multi-metal CEMs that are under development will be located side-byside to allow a comparison. The LIBS technology will be well represented by Sandia National Laboratory and Mississippi State University. The scope of this test is mainly to compare detection limit and relative error compared to EPA Method 29. Laser 
Diagnostics has tentatively requested a port at this test. However, it is not seen as a high priority at this time since the LIBS technology is already well represented at the test. Another possibility is to collaborate with SNL using their test data to perform selfcalibration on-site. This alternative will be pursued in the near future and full participation in the test is still an option.

Participation in other tests in following years is planned. Also, access to a research incinerator that allows development rather than demonstration of capabilities is planned for next fiscal year. 


\section{COLLABORATIONS AND PRESENTATIONS}

\section{Presentations}

"A Continuous Emission Monitor for Toxic Metals in the Off-gases of Thermal Treatment Facilities," FY 1997 CMST-CP Annual Review Meeting, Gaithersburg, MD, 4/17/97.

“A Continuous Calibration Procedure for Reliable LIBS Monitoring of Metals," 1997 International Conference on Incineration and Thermal Treatment Technologies, Oakland, CA, 5/13/97.

\section{Collaborations}

Proprietary Information Agreements with Sandia National Laboratory, Los Alamos National Laboratory, and Physical Sciences, Inc. are in effect. The purpose of these agreements is to share information in the collaborative development or technology transfer of LIBS technology for various applications. The SNL relationship is directly related to the CEM development. The LANL agreement is primarily for the development of a portable soil analyzer. The PSI agreement was recently signed to begin collaboration on single element LIBS sensors that has uses in certain laser ablation applications.

\section{Commercialization}

\section{DOE CAP Utilization}

A rough draft of a business plan has been completed as part of a DOE sponsored Commercialization Assistance Program (CAP). This program has a good tract record in assisting small companies in performing market analysis and strategic planning to obtain financing and making contacts with DOE end-users. Presently we are completing a business plan in preparation for a presentation at an investor / strategic partner workshop in September. This will help to obtain the support needed to make commercial LIBS instruments. 


\section{Single Element Sensors}

In a related project, Laser Diagnostics is making plans to supply small single element sensors to a company in Albuquerque, resulting from collaborative development work between them and Los Alamos National Laboratory as part of an SBIR project at Physical Sciences, Inc. The initial interest is for lead in paint sensors. It would be a simple single emission line detector that is designed for qualitative measurement to meet the needs of the Albuquerque company. The experience gained in the assembly of these sensors by Laser Diagnostics LLC may be useful in the rapid start-up of manufacturing operations for other similar devices, such as a multi-metal CEM.

\section{REFERENCES}

${ }^{1}$ L. J. Radziemski, T. R. Loree, D. A. Cremers, and N. M. Hoffman, Anal. Chem., 55, 1252 , 1983.

2 “Atomic Transition Probabilities: Scandium through Manganese,” G. A. Martin, J. R. Fuhr, and W. L. Wiese, J. Phys. Chem. Ref.Data, 17, Suppl. 3, 1988.

3 “Atomic Transition Probabilities of Carbon, Nitrogen, and Oxygen: A Critical Data Compilation," W. L. Wiese, J. R. Fuhr, and T. M. Deters, J. Phys. Chem. Ref. Data, Monograph 7, 1996.

${ }^{4}$ W. J. Claas, Recherches Astron. Obs. Utrecht 12, Pt. 1 (1951).

${ }^{5}$ D. A. McQuarrie, Statistical Mechanics (Harper \& Row, New York, 1973), pg. 144. 